\title{
How much water is used for irrigation? A new approach exploiting coarse resolution satellite soil moisture products
}

\author{
Luca Brocca $^{\mathrm{a}, *}$, Angelica Tarpanelli ${ }^{\mathrm{a}}$, Paolo Filippucci ${ }^{\mathrm{a}}$, Wouter Dorigo ${ }^{\mathrm{b}}$, Felix Zaussinger ${ }^{\mathrm{b}}$, \\ Alexander Gruber ${ }^{\mathrm{b}, \mathrm{c}}$, Diego Fernández-Prieto ${ }^{\mathrm{d}}$

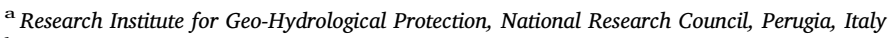 \\ ${ }^{\mathrm{b}}$ CLIMERS - Research Group Climate and Environmental Remote Sensing, Department of Geodesy and Geoinfomation, Vienna University of Technology, Vienna, Austria \\ ${ }^{\mathrm{c}}$ Department of Earth and Environmental Sciences, $K U$ Leuven, Heverlee, Belgium \\ d European Space Agency, ESA-ESRIN, Frascati, Italy
}

\section{A R T I C L E I N F O}

\section{Keywords:}

Soil moisture

Irrigation

Remote sensing

ASCAT

SMAP

SMOS

AMSR2

\begin{abstract}
A B S T R A C T
Knowledge of irrigation is essential for ensuring food and water security, and to cope with the scarcity of water resources, which is expected to exacerbate under the pressure of climate change and population increase. Even though irrigation is likely the most important direct human intervention in the hydrological cycle, we have only partial knowledge on the areas of our planet in which irrigation takes place, and almost no information on the amount of water that is applied for irrigation.

In this study, we developed a new approach exploiting satellite soil moisture observations for quantifying the amount of water applied for irrigation. Through the inversion of the soil water balance equation, and by using satellite soil moisture products as input, the amount of water entering into the soil, and hence irrigation, is determined. Through synthetic experiments, we first assessed the impact of soil moisture measurement uncertainty and temporal resolution, also as a function of climate, on the accuracy of the method. Second, we applied the proposed approach to currently available coarse resolution satellite soil moisture products retrieved from the Soil Moisture Active and Passive mission (SMAP), the Soil Moisture and Ocean Salinity (SMOS) mission, the Advanced SCATterometer (ASCAT), and the Advanced Microwave Scanning Radiometer 2 (AMSR-2). Nine pilot sites in Europe, USA, Australia and Africa were used as case study to test the method in a real-world application.

The synthetic experiment showed that the method is able to quantify irrigation, with satisfactory performance from satellite data with retrieval errors lower than $\sim 0.04 \mathrm{~m}^{3} / \mathrm{m}^{3}$ and revisit times shorter than 3 days. In the case studies based on real satellite data, qualitative assessments (due to missing in situ irrigation observations) showed that over regions in which satellite soil moisture products perform well, and which are characterized by prolonged periods without rainfall, the method shows good results in quantifying irrigation. However, at sites in which rainfall is sustained throughout the year, the proposed method fails in obtaining reliable performances. Similarly, low performances are obtained in areas where satellite products uncertainties are too large, or their spatial resolution is too coarse with respect to the size of the irrigated fields.
\end{abstract}

\section{Introduction}

It is estimated that over $70 \%$ of global freshwater is consumed by irrigation (FAO, 2006; Foley et al., 2011). Irrigated land comprises 1/5 of the world's cultivated area and supplies $2 / 5$ of the world's food (Droogers et al., 2010). Climate change and population growth are expected to further increase the irrigation demand pushing more pressure on available freshwater for food production, and many areas which already experience water scarcity (Vörösmarty et al., 2000;
Rockström et al., 2012; Kummu et al., 2016). Therefore, quantitative knowledge on resources used for irrigation is essential for stakeholders and companies involved in the management of agricultural services and food production that need accurate and timely information for ensuring food and water security (Deines et al., 2017). Additionally, information on irrigation is needed in many research applications e.g., for the assessment of the anthropogenic impact on the water and energy cycle (Bonfils and Lobell, 2007; Wada et al., 2014), to study the water budget closure in large scale hydrological and climate modelling (Döll and

\footnotetext{
* Corresponding author at: Research Institute for Geo-Hydrological Protection, National Research Council, Via della Madonna Alta 126, 06128 Perugia, Italy.

E-mail address: luca.brocca@irpi.cnr.it (L. Brocca).
} 
Siebert, 2002), and for the evaluation of the impact of irrigation on precipitation and evapotranspiration dynamics (Alter et al., 2015).

Notwithstanding the important role of irrigation, its knowledge over large areas and over long periods is nearly absent. Most of the existing irrigation datasets are based on statistical surveys or simply identify areas equipped for irrigation (Salmon et al., 2015; Siebert et al., 2015), and usually are only valid for a specific year or a multi-year period). These datasets are potentially affected by large errors and subjective evaluations thus not being able to capture the spatial-temporal dynamic of irrigated areas (Deines et al., 2017). Alternatively, visible and optical remote sensing has been largely used for estimating irrigated areas (Ozdogan et al., 2010). Recent studies have shown the potential of remote sensing in mapping annual irrigation with high spatial resolution by using Moderate Resolution Imaging Spectroradiometer (MODIS) 250 (Ozdogan and Gutman, 2008; Pervez et al., 2014; Ambika et al., 2016; Teluguntla et al., 2017), Landsat 30 (Deines et al., 2017; Ozdogan et al., 2006; Pun et al., 2017), and geostationary (Romaguera et al., 2012) satellite imagery. Very recently, Sentinel-2 images, characterized by higher spatial resolution $(10 \mathrm{~m})$, have also been used for this purpose (Calera et al., 2017; Ferrant et al., 2017) and in the near future constellations of small satellites, e.g., cubesats, are expected to be very valuable for this purpose (McCabe et al., 2017).

While detecting irrigated areas has been widely investigated, the quantification of the water amount actually used for irrigation is much more problematic. Ground-based observations are essentially non-existent, except for very limited areas $\left(<1-10 \mathrm{~km}^{2}\right)$ and/or time periods ( $<2-3$ years). Technical constraints, i.e., deployment of monitoring systems, and economic limitations, i.e., the cost of water and non-legal consumptions, impede an accurate determination of the actual water volume used for irrigation (see e.g., http://www.fao.org/nr/water/ aquastat/irrigationmap/index40.stm), even on very local scales. Many existing studies focused on modelling irrigation water requirements but not on the actual water used for irrigation (Wada et al., 2014; Döll and Siebert, 2002). As most croplands are often over- or under-irrigated (Foley et al., 2011), the estimated irrigation water requirement is not necessarily equivalent to the actual irrigated water amount.

Also for the irrigation quantification, remote sensing can offer some solutions for monitoring the irrigation water use. Several studies exploited actual evapotranspiration $\left(E T_{a}\right)$, estimates from remote sensing (e.g., MODIS and Landsat) and waterenergy balance modelling approaches to assess irrigation water amounts (Droogers et al., 2010; Romaguera et al., 2010; Wu et al., 2015; van Dijk et al., 2018). For instance, van Eekelen et al. (2015) employed the surface energy balance algorithm for land, SEBAL (Bastiaanssen et al., 1998) for mapping total $E T_{a}$ that is split in $E T_{a}$ induced by precipitation (for rainfed agro-ecosystems) and that by water withdrawals. The latter term is then used for indirectly estimating the water withdrawals for irrigation. The method was applied to the Incomati basin in Southern Africa obtaining annual values of irrigation withdrawals. The main problem of this study, as well as other similar ones, is the absence of in situ irrigation water observations, which makes it extremely difficult to evaluate the reliability and accuracy of the obtained estimates.

In addition to optical and thermal sensors, microwave sensors, which are able to provide estimates of soil moisture, can be used for detecting and quantifying irrigation due to the obvious increase in soil moisture after irrigation (Brocca et al., 2017; Jalilvand et al., under review; Kumar et al., 2015; Malbéteau et al., 2018; Singh et al., 2017; Zaussinger et al., 2018). The first study investigating this approach was carried out by Kumar et al. (2015) who used satellite soil moisture observations from ASCAT (Advanced SCATterometer), AMSR-E (Advanced Microwave Scanning Radiometer - Earth Observing System), SMOS (Soil Moisture and Ocean Salinity), ESA CCI SM (European Space Agency Climate Change Initiative Soil Moisture) and Windsat for the detection of irrigation over the Contiguous United States. By comparing modelled (by the Noah land surface model) and satellite soil moisture data, irrigated areas are inferred from (positive) biases between satellite and modelled data, as the latter does not include irrigation. The confounding effects of topography, vegetation, frozen soils and Radio Frequency Interference (RFI) prevented a clear identification of the irrigated areas even though some potential by using the ASCAT soil moisture product was observed over the plains of Nebraska. Qiu et al. (2016) evaluated soil moisture (from the ESA CCI SM product) and rainfall trend in China and found that satellite data can be used to detect irrigated areas as over those areas trends in satellite soil moisture and rainfall were significantly different. These differences were particularly significant over eastern China, where irrigation is quite extensive. Escorihuela and Quintana-Segui (2016) compared satellite soil moisture (from ASCAT, AMSR-E, SMOS and SMOScat - a MODISdownscaled version of the official SMOS product) and modelled (by the SURFEX - Surface Externalisée - land surface model) data in the Northeast of the Iberian Peninsula. For the high resolution SMOScat product $(1 \mathrm{~km})$, a clear decrease in correlation between modelled and satellite data was observed at a small heavily irrigated region. Indeed, the land surface model does not take irrigation into account, and the low correlation was considered as an indication that SMOScat is able to detect the information of irrigation. Very recently, Lawston et al. (2017) used the new version of the Soil Moisture Active and Passive (SMAP) product at $9 \mathrm{~km}$ sampling for detecting the irrigation signal at three locations in the Western United States. As also shown in a modelling study by He et al. (2017), SMAP seems to be able to detect the irrigation signal, particularly in the Sacramento valley (California), while in the other two locations the results are less accurate.

In this study, we exploit satellite soil moisture information for quantifying the amount of water applied for irrigation. Specifically, we have developed an adapted version of the SM2RAIN algorithm (Brocca et al., 2014a) to estimate the total amount of water entering into the soil. Over irrigated areas, the SM2RAIN-derived water flux is composed of rainfall plus irrigation. Therefore, by removing the rainfall signal (e.g., obtained from rain gauge observations), we could be able to quantify irrigation. In two preliminary studies, Brocca et al. (2017) and Jalilvand et al. (under review) have demonstrated the feasibility of the proposed approach for two single locations in Nebraska and Iran (Urmia lake) and advocated the need to extend the analysis over multiple sites worldwide.

Two research questions are addressed here: 1 ) are we able to extract irrigation water information from coarse resolution satellite soil moisture observations? 2) which climatic and irrigation conditions are most favourable for estimating irrigation through coarse resolution satellite soil moisture observations?

Firstly, we perform a synthetic study with varying climatic, soil, and irrigation conditions in order to assess the potential of the proposed approach in a controlled environment. We also test different configurations for soil moisture observations with varying temporal resolution and uncertainty. Secondly, we apply the method at 9 pilot sites in Europe, USA, Australia and Africa by using all the current available coarse resolution satellite soil moisture products obtained by: 1) the SMAP mission; 2) the SMOS mission; 3) the ASCAT sensor on-board the Metop satellites; and 4) the Advanced Microwave Scanning Radiometer 2, AMSR2, sensor on-board the Global Change Observation Mission Water, GCOM-W1.

The paper is organized as follows. The pilot sites and datasets are described in Sections 2 and 3. The adapted SM2RAIN method is described in Section 4 including details concerning the implementation of the synthetic and real-world experiments. Results are shown and discussed in Section 5. Finally, conclusions are drawn in Section 6.

\section{Pilot sites}

For the real-world analysis, we select 9 pilot sites located in the United States (US), Europe, Africa and Australia (see Fig. 1). The main driver for the selection of the sites is the presence of large scale irrigation over areas comparable to the spatial resolution of the used 

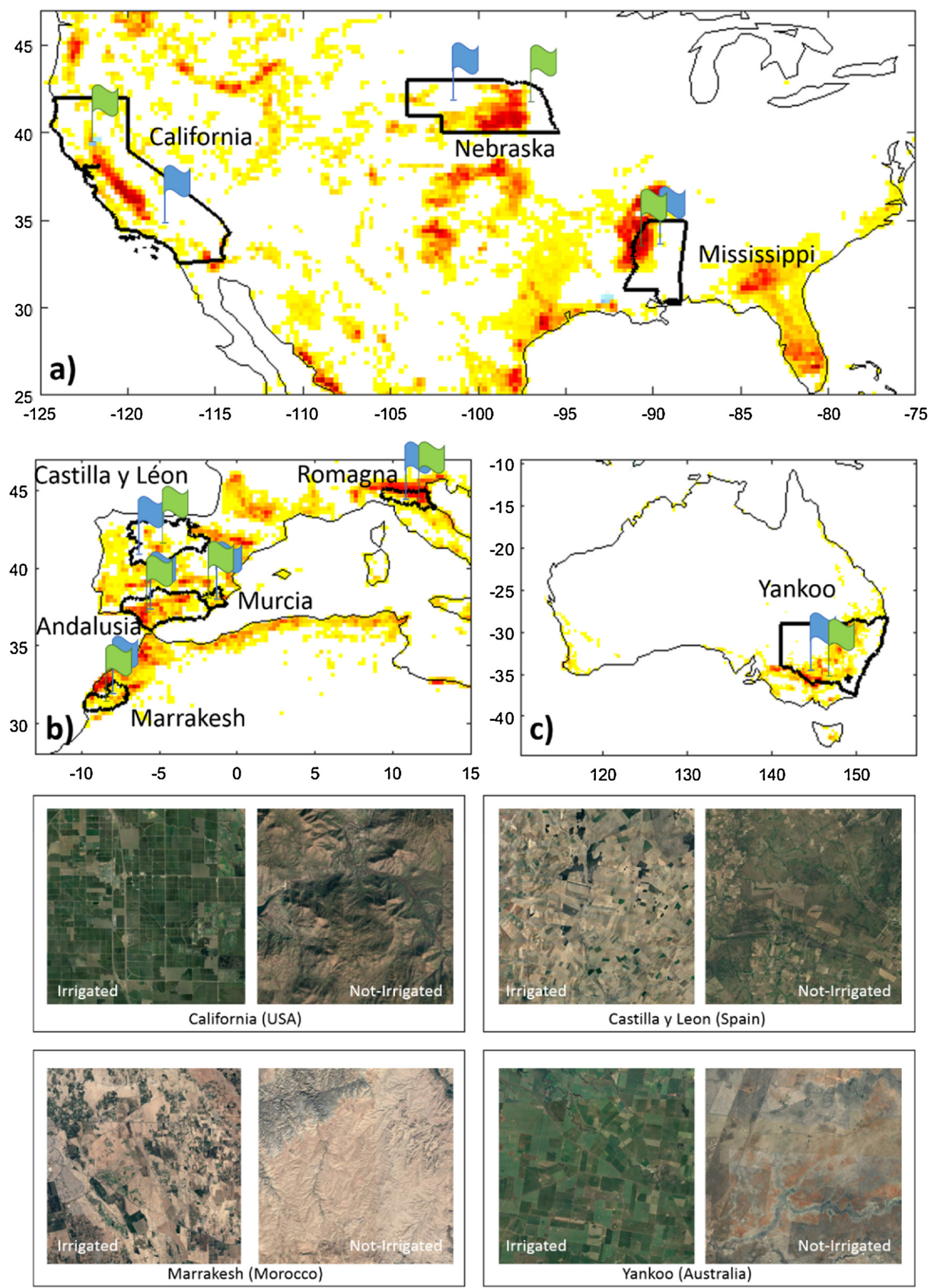

Fig. 1. Location of the pilot sites in the United States of America (a), south-western Europe and north-wester Africa (b), and south-eastern Australia (c). Green (red) flags show the central pixel of irrigated (non-irrigated) areas. The underlying map shows the areas equipped for irrigation (Salmon et al., 2015) with reddish colours for higher density of irrigation equipment. The four bottom figures show examples of irrigated and non-irrigated pixels in USA, Spain, Morocco and Australia. (For interpretation of the references to colour in this figure legend, the reader is referred to the web version of this article).

satellite soil moisture products. Moreover, various climatic conditions and agricultural practices are considered.

The three sites in the US (California's Central Valley, plain of Nebraska and lower Mississippi Basin) are characterized by large scale irrigated areas as can be inferred from the map of the areas equipped for irrigation (Salmon et al., 2015) and, indeed, have been the object of previous studies (Kumar et al., 2015; Lawston et al., 2017). The three US sites are characterized by different climates. The Sacramento Valley, which is part of the California Central Valley has a semi-arid climate and is mainly dedicated to the production of rice. Therefore, the fields 
are first flooded in late April, early May, and sustained until August. The plain of Nebraska is characterized by abundant sprinkler irrigation with cold and snowy winters. The lower Mississippi Basin is one of the most productive agricultural regions in the United States, and the basin is second only to California in total groundwater pumped for irrigation. The basin lies within the humid subtropical climatic zone and, similarly to the Nebraska plain, irrigation is used to ensure a high level of yield. In Europe we selected four sites, three in Spain and one in Italy. In Spain, we selected the Andalusia, Murcia and Castilla y León (close to the REMEDHUS network, Martinez-Fernandez and Ceballos, 2005) regions; in Italy we considered one site in the Pianura Padana (Romagna). All the sites in Europe are characterized by Mediterranean climate with dry summers (low rainfall amounts), particularly in the Andalusia and Murcia regions. Irrigation is widespread in these regions. However, differently from US sites, small fields with different cultivations are usually present, thus characterized by different time periods in which irrigation takes place, and by different methods used for this purpose (sprinkler, drip, gravity irrigation). In Morocco we selected one site around the city of Marrakech with semi-arid climate and low annual precipitation ( $\sim 250 \mathrm{~mm}$ /year, Malbéteau et al., 2018). In Australia we selected a site around the Yanco area (Murrumbidgee catchment) which is a region intensively monitored with ground based soil moisture stations (Smith et al., 2012). The climate is semi-arid and extensive irrigation is applied in the whole region (Malbéteau et al., 2018).

The major limitation of this study is the unavailability of in situ irrigation observations to be used for assessing the performances of the proposed approach. However, though a large effort was made in trying to obtain such data at the pilot sites, they were simply not available. The only exception is for the Spanish sites in which annual values of irrigation at regional level were available through the Instituto Nacional de Estadística. These data represent the average amount of water used for irrigation (mm/year) in the period 2007-2014, although it is not clear how reliable this information is. Moreover, for all pilot sites except those in Australia, we are aware of the months in which irrigation typically occurs and this criterion is considered for a qualitative assessment of the performances of the proposed method.

For each site, we selected two neighbouring pixels $\left(25 \times 25 \mathrm{~km}^{2}\right)$ in irrigated areas (according to the map of the areas equipped for irrigation, Salmon et al., 2015) and two neighbouring pixels in non-irrigated areas. Two 0.25-degree pixels are selected as a compromise between the actual spatial resolution of satellite soil moisture products $(\sim 40 \mathrm{~km})$ and to keep the investigated area as small as possible. Therefore, we are able to test the differences in the irrigation signal detected from satellite soil moisture data for irrigated and non-irrigated areas.

\section{Satellite and ground-based datasets}

\subsection{Satellite soil moisture datasets}

Currently, coarse resolution satellite soil moisture products are available from different microwave sensors operating at X-, C-, and Lband. For this study, we considered four different satellite sensors/ missions and different retrieval algorithms.

The SMAP mission, launched on January 2015, was dedicated to the retrieval of soil moisture from the combined use of active and passive Lband microwave sensors (Entekhabi et al., 2010). Due to the early failure of the active sensor, currently SMAP provides satellite surface soil moisture data (soil layer depth $\sim 5 \mathrm{~cm}$ ) from the passive microwave radiometer at a nominal spatial resolution of $36 \mathrm{~km}$ and a revisit time of 3 days. For this study, we considered the official SMAP level 3 (version 4) surface soil moisture product that includes ascending and descending orbits and has a spatial sampling of $36 \mathrm{~km}$.

The SMOS mission was launched on November 2009 and it was the first L-band microwave radiometer launched in orbit (Kerr et al., 2001). The surface soil moisture product (depth $\sim 5 \mathrm{~cm}$ ) obtained by SMOS has a nominal spatial resolution of $\sim 40 \mathrm{~km}$ and 3 days of revisit time. We used the official SMOS level 3 surface soil moisture product distributed by Centre Aval de Traitement des Données SMOS (CATDS) which includes ascending and descending orbits and has a spatial sampling of $\sim 0.25^{\circ}(\sim 25 \mathrm{~km})$.

ASCAT is a C-band scatterometer currently on board the Metop-A and Metop-B satellites which were launched on October 2006 and September 2012, respectively. The TU Wien retrieval algorithm (Wagner et al., 2013) is used for obtaining surface soil moisture data (depth $\sim 2.5 \mathrm{~cm}$ ) from ASCAT backscattering observations with a spatial resolution of $25 \mathrm{~km}$ and a nearly daily revisit time. The H SAF (EUMETSAT Satellite Application Facility on Support to Operational Hydrology and Water Management) H111 soil moisture product is used here. The product includes ascending and descending orbits and has a spatial sampling of $12.5 \mathrm{~km}$. We also used a modified version of H111, which includes a dynamical correction of vegetation backscatter (Vreugdenhil et al., 2016); in H111 the (seasonally varying) correction of vegetation is constant for all years.

AMSR2 is a multi-frequency radiometer launched on board the GCOM-W1 satellite on May 2012. Two retrieval algorithms for AMSR2 brightness temperature observations are considered: the Land Parameter Retrieval Model (LPRM, Owe et al., 2008) and the JAXA (Japan Aerospace Exploration Agency) algorithm (Kim et al., 2015). Specifically, three different products are released from the application of LPRM to AMSR2 data based on the main wavelength used for soil moisture retrieval, i.e., band $\mathrm{C}$ ( 2 wavelengths, $\mathrm{c} 1=6.925 \mathrm{GHz}$ and $\mathrm{c} 2=7.3 \mathrm{GHz}$ ) and band $\mathrm{X}$. Therefore, four surface soil moisture (depth $\sim 2.5 \mathrm{~cm}$ ) products from AMSR2 are analysed, all of them including both ascending and descending orbits, and with a spatial sampling of $0.25^{\circ}(\sim 25 \mathrm{~km})$.

\subsection{Satellite and ground-based meteorological datasets}

For each pilot site, and specifically for each pixel considered in the analysis, we collected ground- and satellite-based rainfall and air temperature data to be used as input observations in the SM2RAIN algorithm. Daily rainfall observations are taken from different data sources including: the gauge-based Climate Prediction Center (CPC) product for the US sites, the European high-resolution gridded data sets (E-OBS, Haylock et al., 2008) for the Spanish sites, the Multi-Source WeightedEnsemble Precipitation (MSWEP) version 2.0 (Beck et al., 2017a, 2017b) for the Morocco site, the Australian Water Availability Project (AWAP) dataset (Jones et al., 2009) for the Australian site and the Italian Civil Protection Department gauge-based dataset (Ciabatta et al., 2017) for the Italian site. The selection of the rainfall datasets was carried out through a preliminary analysis in which we checked the quality of each dataset at each site. Daily air temperature observations are extracted from the NCEP-NCAR reanalysis project (Kalnay et al., 1996) and are available on a global scale at 2.5-degree resolution.

\section{Method}

\subsection{Theoretical background of the SM2RAIN algorithm}

The SM2RAIN algorithm is based on the inversion of the soil water balance equation and allows to estimate the amount of water entering into the soil by using as input soil moisture information. SM2RAIN was initially developed to retrieve rainfall from in situ and satellite soil moisture data (Brocca et al., 2015, 2016, 2017; Koster et al., 2016; Ciabatta et al., 2017; Massari et al., 2017a). In this study, we adapted the SM2RAIN algorithm for quantifying irrigation over agricultural regions. Specifically, the soil water balance equation can be described by the following equation:

$n Z \frac{d S(t)}{d t}=r(t)+i(t)-g(t)-s r(t)-e(t)$

where $n[-]$ is the soil porosity, $Z[\mathrm{~mm}]$ is the soil layer depth, $S(t)[-]$ is 


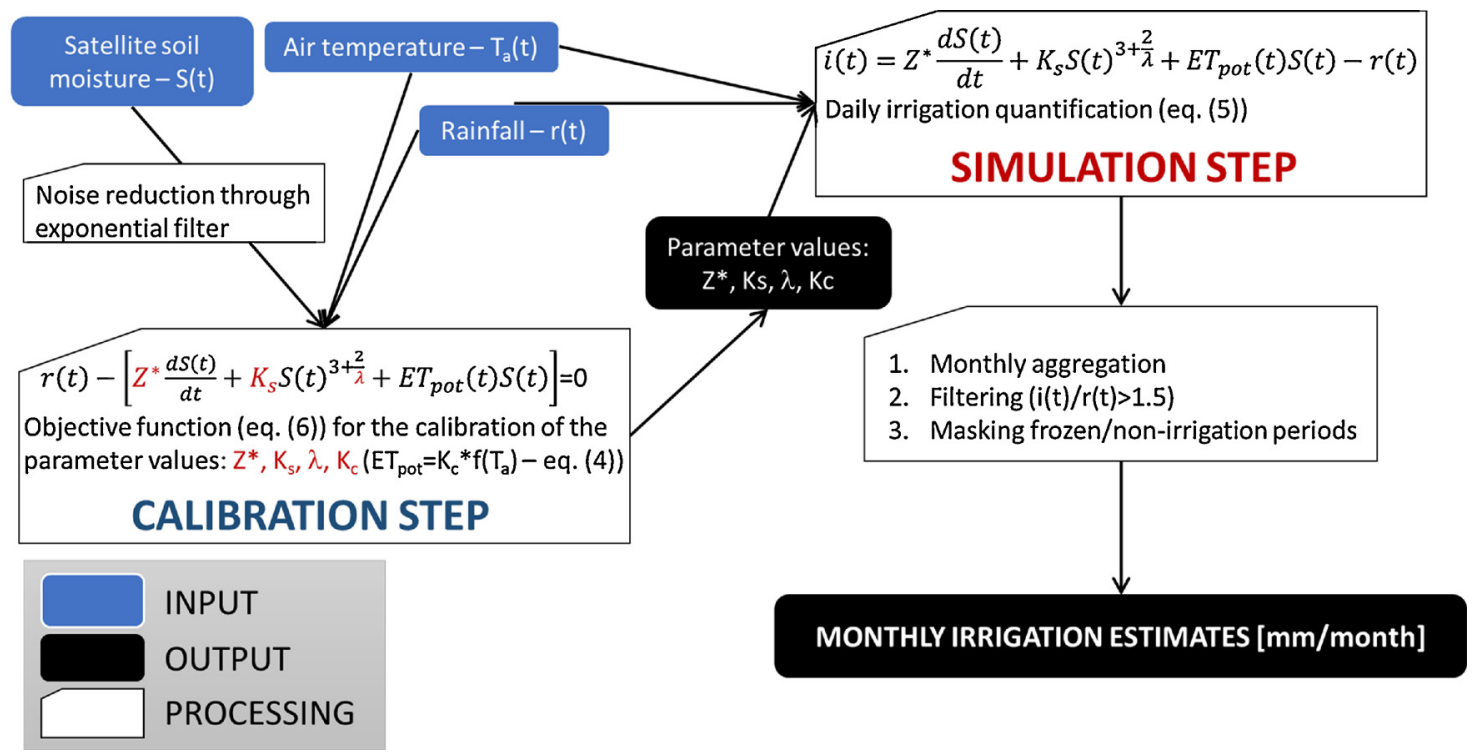

Fig. 2. Flow chart of the method used for estimating irrigation from satellite soil moisture products plus meteorological observations (air temperature and rainfall).

the relative saturation of the soil or relative soil moisture, $t$ [days] is the time, $r(t)[\mathrm{mm} /$ days $]$ is the rainfall rate, $i(t)[\mathrm{mm} /$ days $]$ is the irrigation rate, $g(t)[\mathrm{mm} /$ days] is the drainage (deep percolation plus subsurface runoff) rate, $\operatorname{sr}(t)[\mathrm{mm} /$ days $]$ is the surface runoff and $e(t)[\mathrm{mm} /$ days $]$ is the actual evapotranspiration.

The drainage rate is related to the relative soil moisture through a power law equation (Brocca et al., 2014b):

$g(t)=K_{S} S(t)^{3+\frac{2}{\lambda}}$

where $K_{s}[\mathrm{~mm} /$ days $]$ is the saturated hydraulic conductivity and $\lambda[-]$ is the pore size distribution index.

The actual evapotranspiration rate is assumed to be linearly related to potential evapotranspiration, $E T_{p o t}(t)[\mathrm{mm} /$ days $]$ :

$e(t)=E T_{p o t}(t) S(t)$

The potential evapotranspiration is computed through the empirical relation of Blaney and Criddle as modified by Doorenbos and Pruitt (1977):

$E T_{p o t}(t)=K_{c}\left\{-2+1.26\left[\left(0.46 T_{a}(t)+8.13\right)\right]\right\}$

where $T_{a}(t)\left[{ }^{\circ} \mathrm{C}\right]$ is the air temperature, $\xi[-]$ is the percentage of total daytime hours for the period used (daily or monthly) out of total daytime hours of the year $(365 \times 12)$, and $K_{c}$ [-] is a correction factor for taking into account the empirical nature of Eq. (4).

By assuming that the rate of surface runoff is negligible, $\operatorname{sr}(t)=0$ (Brocca et al., 2015), Eq. (1) is rewritten as:

$i(t)=Z^{*} \frac{d S(t)}{d t}+K_{S} S(t)^{3+\frac{2}{\lambda}}+E T_{p o t}(t) S(t)-r(t)$

where $Z^{*}=Z n[\mathrm{~mm}]$ represents the water capacity of the soil layer.

Therefore, Eq. (5) is used for estimating irrigation rate from soil moisture, $S(t)$, air temperature, $T_{a}(t)$, and rainfall, $r(t)$, data. Indeed, irrigation is estimated as the difference between the total amount of water entering into the soil (measured through soil moisture data) and rainfall (last term of Eq. (5)). Four parameters $\left(Z^{*}, K_{s}, \lambda, K_{c}\right)$ need to be estimated as described in the next section.

\subsection{Implementation of SM2RAIN algorithm for irrigation estimation}

In this section, the technical implementation of the adapted SM2RAIN algorithm is described for the synthetic and real-world experiments. The two experiments shared some common features related to the calibration of the parameter values of the algorithm (Eq. (5)). In both cases, the SM2RAIN algorithm is calibrated against reference rainfall data. However, as we suppose that the irrigation water amount is unknown (not true in the synthetic experiment), the calibration of SM2RAIN by considering the days in which rainfall is zero, and irrigation might be greater than zero, implies a possible significant underestimation of the water flux by SM2RAIN. In these days, an increase in soil moisture is observed due to irrigation, but with the rainfall being equal to zero, the calibration will produce wrong parameter values. Therefore, the SM2RAIN calibration was carried out only for those days in which reference rainfall is greater than zero thus assuming that at those dates no irrigation is applied. Therefore, Eq. (5) is simplified to (valid when $i(t)=0$ ):

$r(t)=Z^{*} \frac{d S(t)}{d t}+K_{s} S(t)^{3+\frac{2}{\lambda}}+E T_{p o t}(t) S(t)$

and the reference rainfall can be used for obtaining the four parameters: $Z^{*}, K_{s}, \lambda, K_{c}$.

As objective function, in accordance with previous studies (Brocca et al., 2017), the minimization of the root mean square difference between reference and SM2RAIN-estimated rainfall is considered. For this study, the calibration is carried out by considering 30-day rainfall accumulation as we are interested in obtaining monthly-scale irrigation water estimates. Specifically, Eq. (5) is applied at daily time scale and used for obtaining SM2RAIN-derived rainfall plus daily irrigation rates. Rainfall plus irrigation data are then aggregated to a monthly time scale and the final irrigation estimates are obtained by subtracting the monthly reference rainfall. To account for random errors in the proposed algorithm, we masked out irrigation estimates which are below a specific threshold. We assume that in this case irrigation is not significant, i.e., lower than the structural rainfall error of the SM2RAIN algorithm. Since rainfall errors are commonly assumed to be multiplicative (Tian et al., 2013), the used threshold depends on the absolute estimated rainfall in the corresponding month. Specifically, irrigation is assumed to be not significant if the ratio between monthly irrigation and the reference monthly rainfall is lower than 1.5 (obtained through a preliminary sensitivity analysis). Negative irrigation estimates are set to zero. We also masked out the winter period in which no irrigation is expected. As a final output, monthly irrigation is obtained. In Fig. 2 a flow chart illustrating the overall approach for the calibration and the simulation steps is given. 


\subsubsection{Synthetic experiments}

In the synthetic experiment, we used the soil water balance model developed in Brocca et al. (2008, 2014b) for simulating surface soil moisture by using meteorological and irrigation data as input. The model was found to be accurate in simulating both the temporal evolution of infiltration, with respect to the exact solution given by the Richard's equation and laboratory data (Morbidelli et al., 2011), and soil moisture, with respect to in situ observations throughout Europe (Brocca et al., 2014b). The soil water balance model is found to correctly represent the physical processes involved in the simulation of soil moisture through rainfall and air temperature data. Therefore, it is an appropriate tool to investigate the reliability of the proposed method (Eq. (5)) for estimating irrigation water amounts.

The synthetic experiments are built as follows. Rainfall and air temperature data from two sites characterized by two different climates, semi-arid in southern Spain (mean annual rainfall $490 \mathrm{~mm} /$ year) and semi-humid in northern Italy (mean annual rainfall $880 \mathrm{~mm} /$ year), are considered. These data are used as input into the soil water balance model for simulating the hourly soil moisture temporal evolution for a layer depth of $10 \mathrm{~cm}$ (if not explicitly stated differently). The parameter values of the soil water balance model used in the simulations are obtained from a previous application at the same sites (Brocca et al., 2015). The obtained soil moisture observations are aggregated at daily time scale and represent the simulated soil moisture without irrigation. Additionally, we considered two different irrigation configurations: 1) low irrigation rate corresponding to $300 \mathrm{~mm}$ /year in the period JulySeptember, and 2) high irrigation rate corresponding to $600 \mathrm{~mm} /$ year in the period July-September (see Fig. 3). Irrigation is applied every week (i.e., one day per week) at a constant rate of $\sim 23 \mathrm{~mm} /$ week ( $\sim 46 \mathrm{~mm} /$ week) to obtain $300 \mathrm{~mm} /$ year $(600 \mathrm{~mm} /$ year). By using the same parameter values, soil moisture is simulated at an hourly time scale and then aggregated to a daily time scale.

The daily simulated soil moisture data (without and with irrigation) are used as input into the SM2RAIN algorithm (Eq. (5)) which is calibrated by using the reference rainfall as benchmark (only non-zero rainfall values) as explained before. Once calibrated, Eq. (5) is applied to the simulated soil moisture with irrigation for estimating monthly irrigation that is compared with the synthetic irrigation observations to assess the performance of the method under idealized conditions.

To obtain a more realistic representation of real-world conditions we perturbed our soil moisture simulations with additive zero-mean Gaussian noise with a standard deviation varying between $0.01 \mathrm{~m}^{3} / \mathrm{m}^{3}$ and $0.08 \mathrm{~m}^{3} / \mathrm{m}^{3}$. For assessing the influence of the revisit time of satellite observations, we also varied revisit times between one day (e.g., ASCAT and AMSR2) and six days (e.g., Sentinel-1). Additionally, we performed a sensitivity analysis also varying the depth of the soil layer between 4 and $16 \mathrm{~cm}$ and the amount of potential evapotranspiration by using a multiplicative factor between 0.5 and 1.5. Results for the above described synthetic scenarios are provided in Section 5.1.

\subsubsection{Real-world experiments}

In the real-world experiment, reference rainfall data are obtained from raingauge or merged satellite-gauge products as mentioned before (see Table 1 for details). Specifically, all the products are gridded onto a regular grid with a 0.25 -degree spacing, and the average rainfall and air temperature for the two irrigated and non-irrigated pixels are computed. Air temperature is used for computing potential evapotranspiration (Eq. (4)) while reference rainfall is used for the calibration of the SM2RAIN parameters, which is performed separately at each site (only non-zero rainfall values, Eq. (6)). To mitigate the impact of random noise in the satellite soil moisture retrievals, we apply the exponential filter of Wagner et al. (1999) which essentially acts as a low pass filter that preserves the lower-frequency irrigation signal while removing high-frequency random errors (Brocca et al., 2016). The calibrated SM2RAIN algorithm is used for computing monthly irrigation rates as in the synthetic experiments. The analysis period is 3-year between 2014 and 2016 .

\section{Results and discussions}

\subsection{Synthetic experiments}

Fig. 3 shows the results obtained for the two climates (semi-arid and semi-humid) and for two predefined error levels in soil moisture data: $0.00 \mathrm{~m}^{3} / \mathrm{m}^{3}$, i.e., perfect observations, and $0.04 \mathrm{~m}^{3} / \mathrm{m}^{3}$, which is the target uncertainty of the SMOS and SMAP missions. The configuration with high irrigation rate equal to $600 \mathrm{~mm}$ /year is considered. In the simulations considering no error in soil moisture retrievals (Fig. 3a and c), the capability of the method in reproducing (synthetically generated) true irrigation levels is very good, with a perfect agreement in the semi-humid climate and slightly lower performances in the semi-arid climate. The main problem in the semi-arid climate is observed at the end of the irrigation period in the first year. Indeed, we applied irrigation in the month of September in which a large rainfall amount is observed (100 mm/month). In conditions in which irrigation is applied during months with large rainfall, the method fails in correctly separating irrigation from precipitation. If we assume a random error of 0.04 $\mathrm{m}^{3} / \mathrm{m}^{3}$ the capability of estimating irrigation is reduced (see upper panels of Fig. 3b and d). Indeed, particularly in the semi-arid climate, spurious irrigation signals are obtained in the last year due to noise in the soil moisture data. As before, the irrigation simulated in the semihumid climate shows a better agreement with observations with a slight overestimation due to noise. The better results for the semi-humid climate are mainly due to the higher frequency (and magnitude) of rainfall events that provide a better calibration of the adapted SM2RAIN algorithm with respect to the semi-arid climate.

A more comprehensive analysis of the effect of irrigation intensity, climate, soil moisture error, revisit time, potential evapotranspiration and soil layer depth is shown in Fig. 4. The two top plots (Fig. 4a and b) show the influence of soil moisture error and irrigation intensity on the Pearson's correlation coefficient, $r$, between true and estimated monthly irrigation. 50 realizations are carried out in each configuration to account for stochastic noise. The median $r$-values are shown in Fig. 4. As before, the performances are better in the semi-humid climate nearly independent from the irrigation rate. In the semi-arid climate, performances are worse for the lower irrigation rate $(300 \mathrm{~mm} /$ year $)$ and decrease quickly passing from an error of $0.01 \mathrm{~m}^{3} / \mathrm{m}^{3}$ to $0.03 \mathrm{~m}^{3} / \mathrm{m}^{3}$. For larger errors, the performance converges to an $r$-value of 0.7 . In the semi-humid case, $r$-values are much larger $(r>0.9)$ and a decrease in the performance is visible only for errors larger than $0.06 \mathrm{~m}^{3} / \mathrm{m}^{3}$. Fig. $4 \mathrm{c}$ and $\mathrm{d}$ show the influence of revisit time which is found to have a larger impact on the results. Indeed, a larger deterioration in the performance is observed, in this case with similar reductions for both the semi-arid and semi-humid climate. If we assume perfect observations (continuous lines in Fig. 4c and d), for a revisit time larger than three days the $r$-values show a significant deterioration. When considering an error of $0.04 \mathrm{~m}^{3} / \mathrm{m}^{3}$ the performances are lower, particularly for the semi-arid climate. Interestingly, the $r$-values in the semi-arid climate for a low irrigation rate $\left(300 \mathrm{~mm} /\right.$ year) and an error of $0.04 \mathrm{~m}^{3} / \mathrm{m}^{3}$ are quite low and not varying with revisit time. The influence of potential evapotranspiration is shown in Fig. 4e and $\mathrm{f}$ in which a multiplicative factor is considered for increasing or decreasing the "observed" value of potential evapotranspiration. In this case, the method shows null to low sensitivity due to the capability of SM2RAIN to adapt the parameter values to arrange the different magnitude of evapotranspiration. Similarly, the method shows very low sensitivity to the soil layer depth (Fig. $4 \mathrm{~g}$ and h). For the semi-humid climate, better performances are obtained for a shallower layer depth due to its higher sensitivity to the rainfall and irrigation input from the atmosphere. Therefore, the shallow soil layer depth seen from satellite sensors is suitable for irrigation quantification.

The results of the synthetic experiment indicate that the adapted 


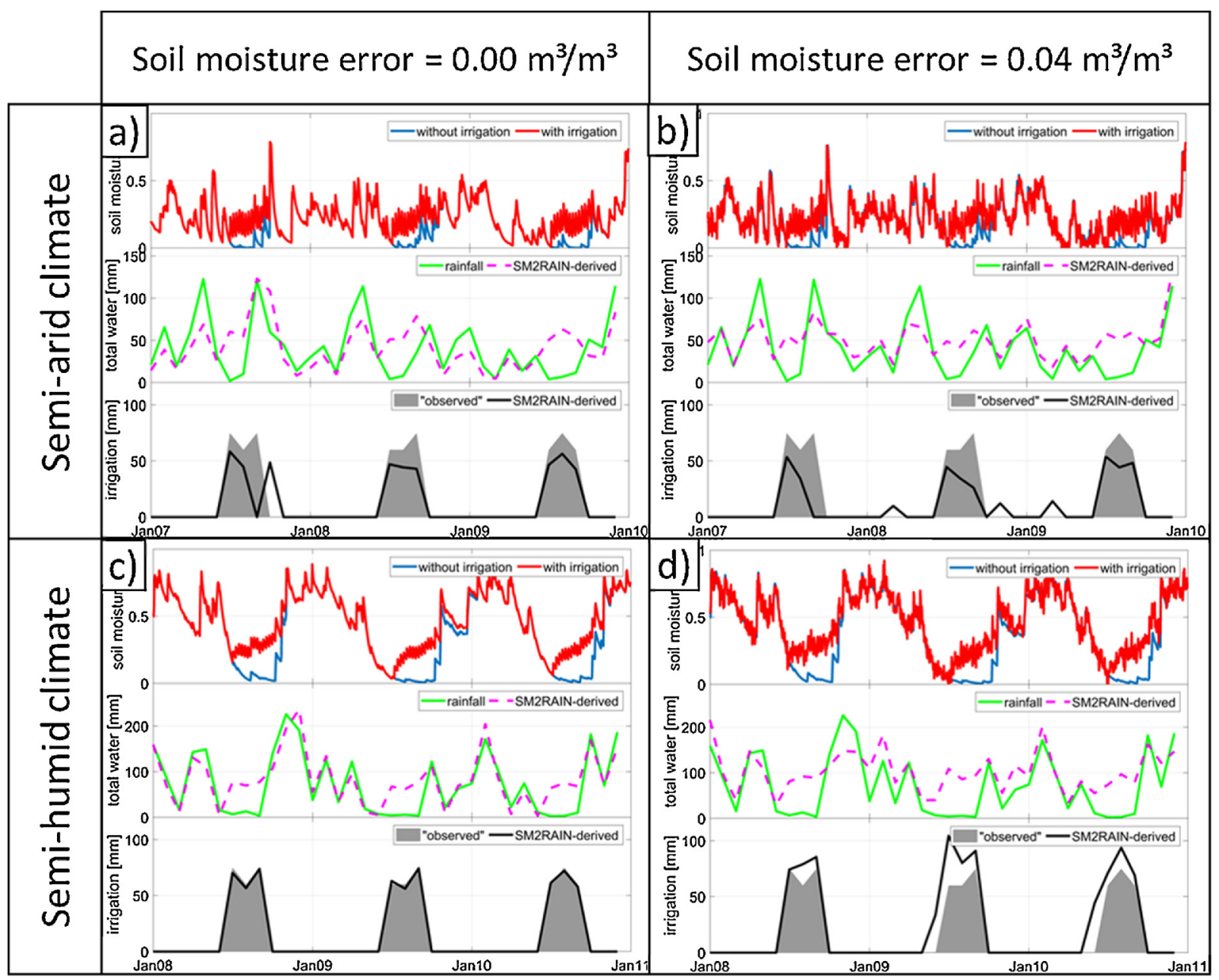

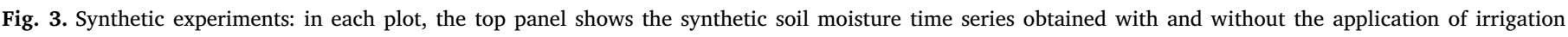

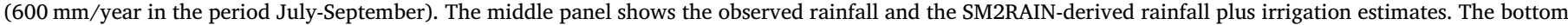

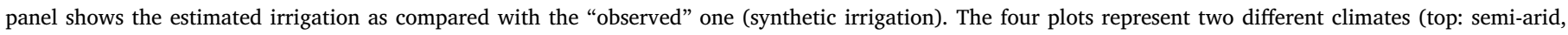
bottom: semi-humid) and two different errors on soil moisture data (left: $0.00 \mathrm{~m}^{3} / \mathrm{m}^{3}$, i.e., perfect observations, right: $0.04 \mathrm{~m} / \mathrm{m}^{3}$ ).

SM2RAIN approach is able to provide an estimation of monthly irrigation with better performances in semi-humid climate and for larger irrigation rates. Revisit time is found to have a larger influence on the performance than random errors. Potential evapotranspiration and soil layer depth have a null to low impact on the method performances. In summary, uncertainties larger than $0.03 \mathrm{~m}^{3} / \mathrm{m}^{3}\left(0.06 \mathrm{~m}^{3} / \mathrm{m}^{3}\right)$ and revisit times larger than three days can be considered as threshold values in semi-arid (semi-humid) climate beyond which we can expect a low reliability of irrigation estimates.

\subsection{Real-world experiments}

As preliminary analysis, we assessed the capability of the different satellite soil moisture products to reproduce observed rainfall estimates through SM2RAIN. A total number of eight satellite soil moisture products is analysed: SMAP, SMOS, two algorithms for ASCAT, three bands for AMSR2-LPRM, and AMSR2-JAXA. For each pilot site, we selected 16 pixels neighbouring the irrigated pixels shown in Fig. 1, and for each pixel we computed daily rainfall through SM2RAIN corresponding to non-zero values of reference rainfall. By analysing these results, we

Table 1

Main characteristics of the selected pilot sites (ET: evapotranspiration; Long.: longitude, Lat.: latitude).

\begin{tabular}{|c|c|c|c|c|c|}
\hline \multirow[t]{2}{*}{ Pilot site } & \multirow[t]{2}{*}{ Climate } & \multirow[t]{2}{*}{ Annual precipitation (mm) } & \multirow[t]{2}{*}{ Annual potential ET (mm) } & \multicolumn{2}{|l|}{ Long./Lat. } \\
\hline & & & & Irrigated & Non-irrigated \\
\hline California Central Valley (US) & semi-arid & $320(C P C)$ & 1170 & $-122.0 / 39.3$ & $-119.1 / 35.4$ \\
\hline Nebraska Plain (US) & semi-humid & $660(C P C)$ & 970 & $-96.9 / 41.9$ & $-101.8 / 41.9$ \\
\hline Lower Mississippi Basin (US) & humid & $1250(C P C)$ & 1320 & $-90.9 / 33.5$ & $-89.9 / 33.8$ \\
\hline Marrakech (Morocco) & semi-arid & 350 (MSWEP) & 1400 & $-7.6 / 31.5$ & $-8.2 / 31.4$ \\
\hline Andalusia (Spain) & semi-arid & $550(E O B S)$ & 1340 & $-5.3 / 37.8$ & $-5.3 / 37.4$ \\
\hline Murcia (Spain) & semi-arid & 320 (EOBS) & 1380 & $-2.2 / 38.1$ & $-1.4 / 38.1$ \\
\hline Castilla y León (Spain) & semi-arid & 430 (EOBS) & 1080 & $-5.1 / 41.1$ & $-6.6 / 40.9$ \\
\hline Romagna (Italy) & semi-humid & $690(D P C)$ & 970 & $11.8 / 44.6$ & $11.0 / 44.3$ \\
\hline Yanco (Australia) & semi-arid & $530(A W A P)$ & 1210 & $146.7 /-35.7$ & $144.9 /-34.0$ \\
\hline
\end{tabular}




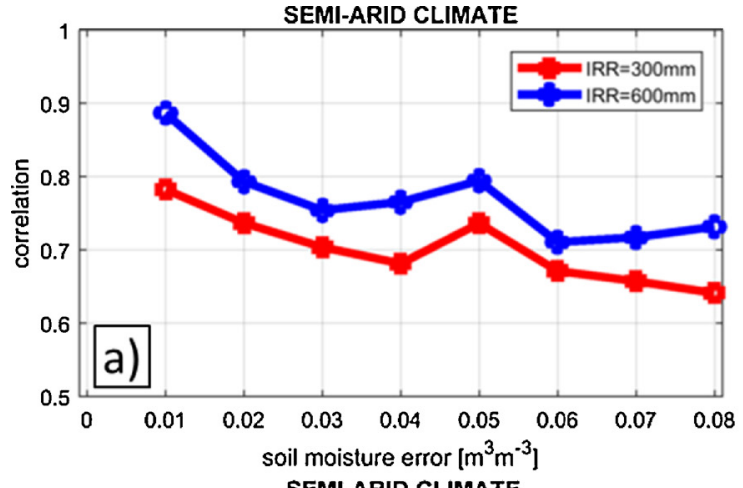

SEMI-ARID CLIMATE

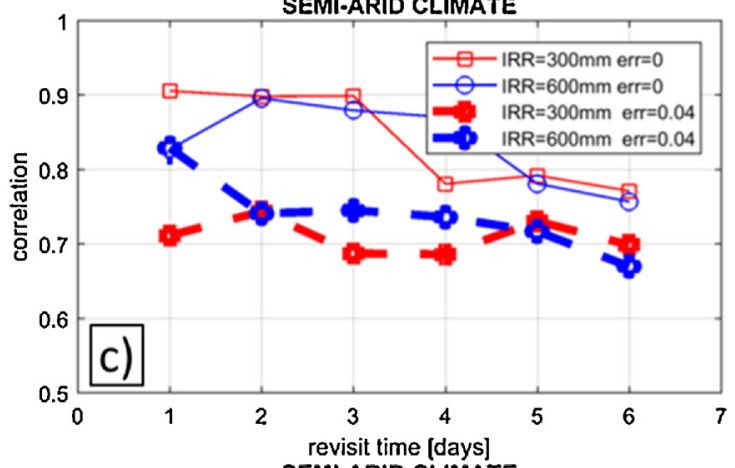

SEMI-ARID CLIMATE

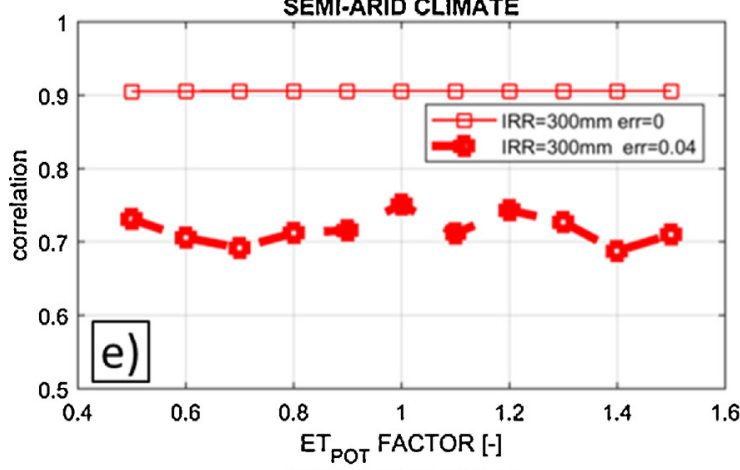

SEMI-ARID CLIMATE

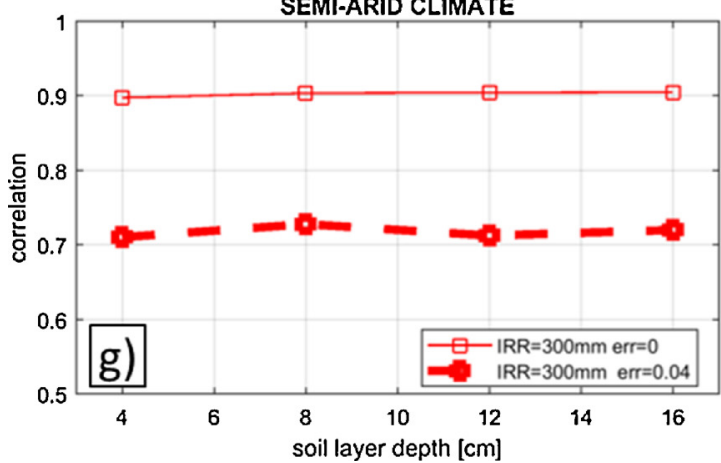

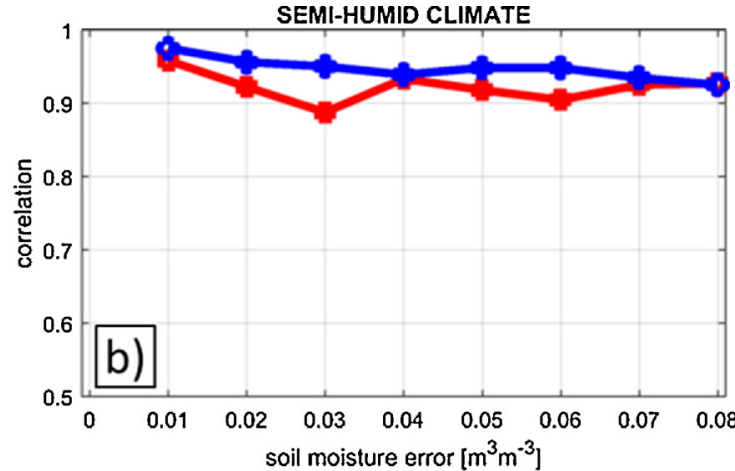

SEMI-HUMID CLIMATE

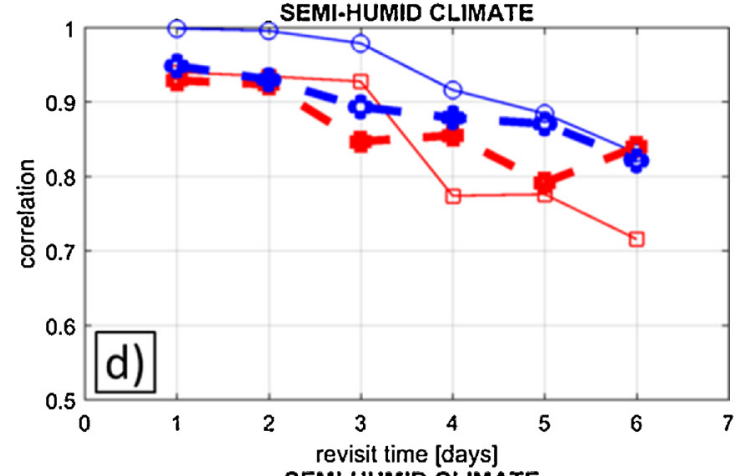

SEMI-HUMID CLIMATE

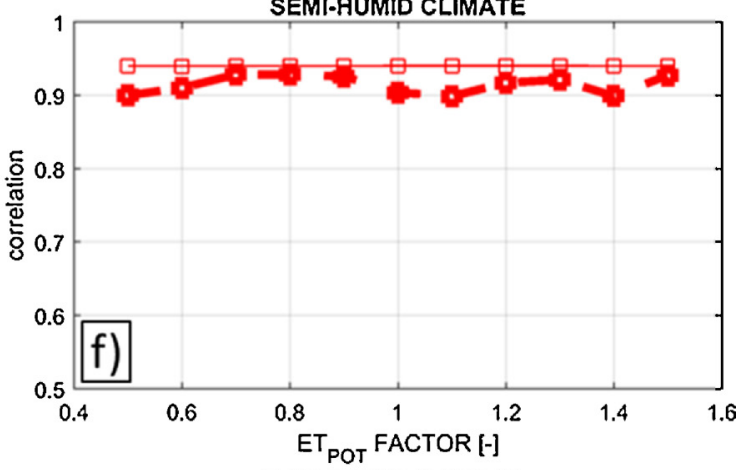

SEMI-HUMID CLIMATE

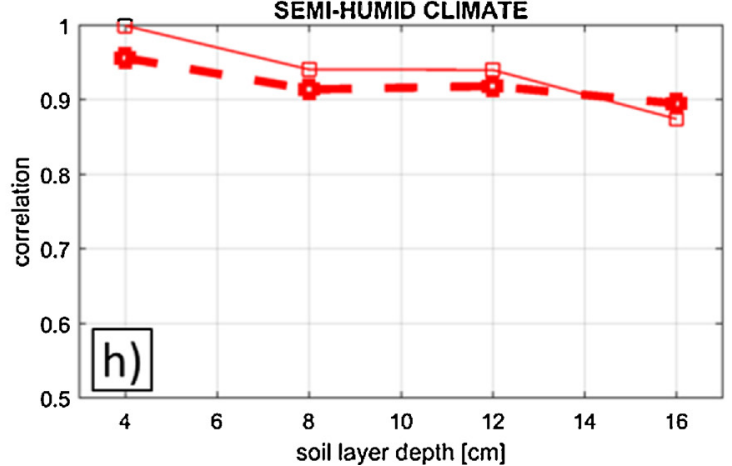

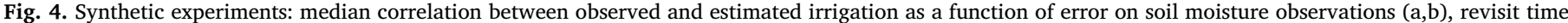

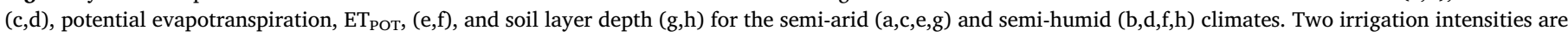

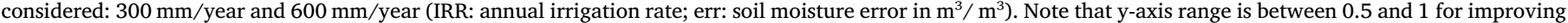
the visualization of the differences between the simulations.

selected the best performing product for ASCAT, i.e., the one considering the dynamical correction of vegetation (Hahn et al., 2017), and for AMSR2-LPRM, i.e., band C2 $(7.3 \mathrm{GHz})$. Therefore, we finally selected the 5 soil moisture products to be used for estimating irrigation. The performance in terms of monthly rainfall estimation at each pilot sites is shown in Fig. 5. Overall, the best performing product is SMAP, with median $r$-values greater than 0.9 except for the Lower Mississippi Basin. We should also underline that SMAP data are only available for a period of 20 months (March 2015 - December 2016) while the other products are available for the full 3-year period. The SMOS product is performing satisfactorily at US sites and in Australia, ASCAT shows good results at all sites except the Lower Mississippi Basin, and the two AMSR2 products perform similarly with slightly better performance for AMSR2-LPRM than for AMSR2-JAXA. The overall ranking of the products in terms of monthly rainfall estimation is: SMAP (median $r=0.95)$, ASCAT (0.87), AMSR2-LPRM (0.82), AMSR2-JAXA (0.77), 


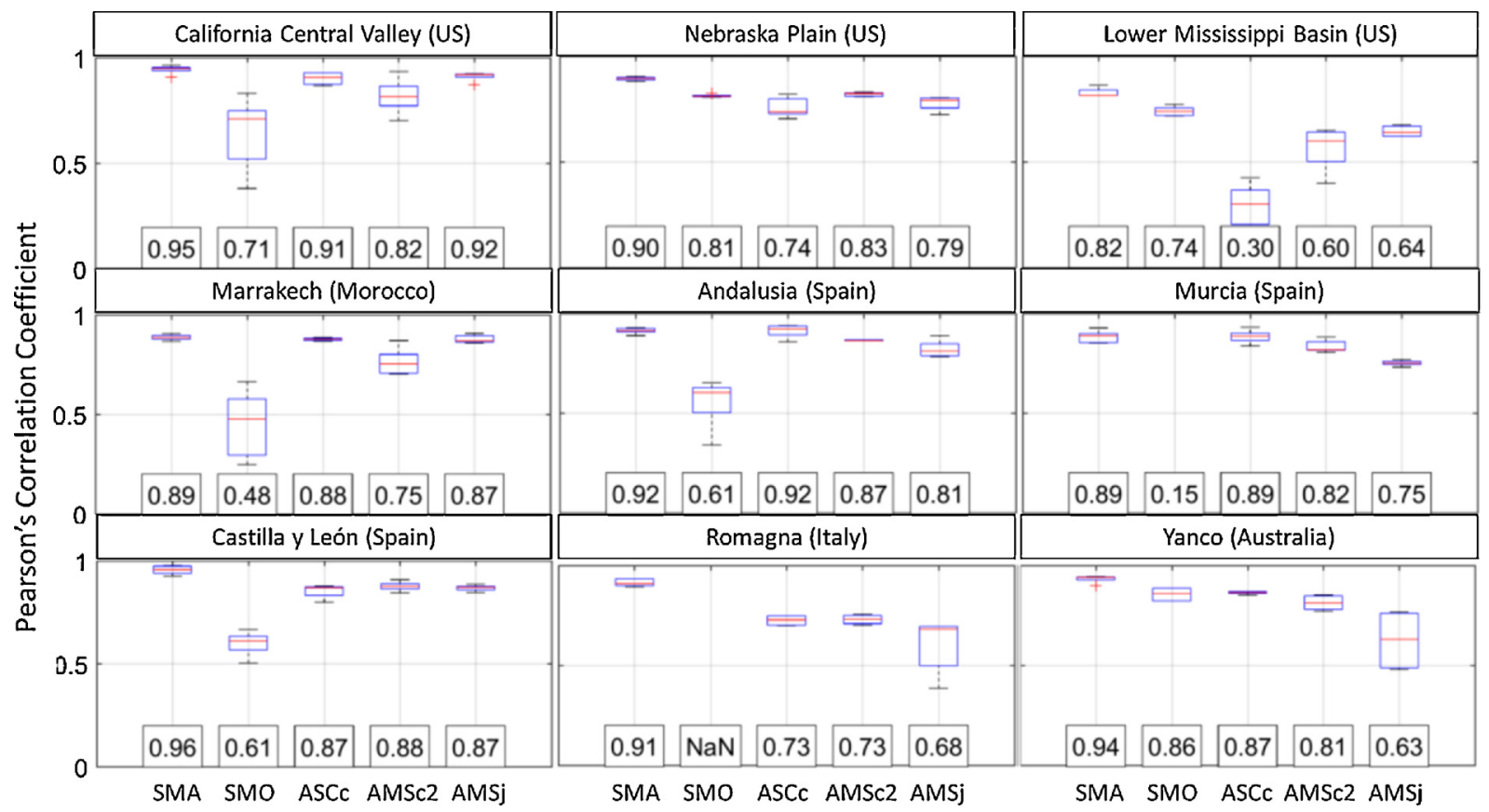

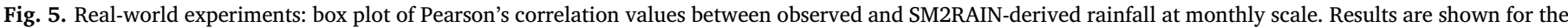

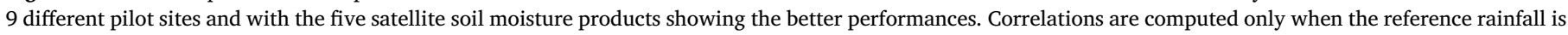
greater than zero (SMA: SMAP; SMO: SMOS; ASCc: ASCAT with dynamic vegetation correction; AMSc2: AMSR2-LPRM c2-band; AMSj: AMSR2-JAXA).

and SMOS (0.66). It should be underlined that RFI significantly affects SMOS accuracy at the Romagna (Italy) site and in Spain. Moreover, the lower revisit time of SMOS (three days as opposed to one day for ASCAT and AMSR2) is another limitation for using such a product alone for rainfall estimation through SM2RAIN.

Figs. 6 and 7 summarize our real-world results for all considered products and pilot sites. As mentioned before, the major limitation of this analysis is the lack of reliable reference irrigation information that should be used for validating the method. Therefore, we adopted a qualitative approach for assessing the reliability of the irrigation estimation method. First, we know the periods (months) in which irrigation typically occurs, and the method is assumed to be reliable if it correctly identifies irrigation in these periods. Second, if there is consistency between estimates from the different satellite soil moisture products, this provides a certain level of confidence that the derived signals are indeed resulting from irrigation. Third, we expect that the soil moisture products which performs better in terms of rainfall retrieval (Fig. 4) can be considered as "reference" also for estimating irrigation (i.e., SMAP).

Based on the criteria selected above, from Figs. 6 and 7 we assume that the irrigation estimates for the sites in California, Morocco and Spain can be considered reliable. Indeed, for these sites the irrigation estimates between the satellite soil moisture products are consistent with each other (remember though that SMAP is available only from 2015), occur in the expected time period (summer season), and show realistically larger values in California where irrigation is known to be abundant. In California, we observe soil moisture increases in periods without rainfall, clearly showing a signal of irrigation in satellite soil moisture data (particularly evident in SMAP and SMOS). SMAP and SMOS based results are very consistent with each other, while the Cband ASCAT and AMSR2-LPRM results show an irrigation signal 1-2 months later than the L-band products, AMSR2-JAXA shows a behaviour close to SMAP and SMOS. As ASCAT is an active sensor, it might be due to specular reflection of the signal in flooded rice fields. Moreover, these differences could be attributed to the way in which vegetation is modelled in the retrieval algorithms. Clearly, an in-depth investigation is needed to disentangle the different components affecting the active/passive microwave signals in irrigated areas.
At the other sites (Nebraska, Mississippi, Italy, and Australia), at least one of the above criteria is not met. For instance, in Nebraska irrigation takes place in the months July-September, and it seems to be correctly identified by the ASCAT product (see the higher soil moisture values of ASCAT in the top panel of Fig. 5). However, due to the occurrence of significant rainfall in the irrigation period, the proposed method is not able to estimate the irrigation amount at this site and, likely, a different configuration of the method (e.g., different threshold for non-significant irrigation, weekly aggregation of the data) would be required. In the Mississippi region, ASCAT and AMSR2 products show a strong irrigation signal in the months August-September, which is not captured by SMOS and SMAP, although the latter two showed better performances in terms of rainfall retrieval (Fig. 5). Therefore, we cannot be sure that the detected irrigation signal is real or an artefact. In Italy, the products are consistent with each other in the years 2015 and 2016 (note that SMOS data are not available due to RFI), but no irrigation is found in 2014. This might be due to the large rainfall that occurred in summer 2014 (230 mm, compared to $\sim 90 \mathrm{~mm}$ in 2015 and 2016) which reduced the need of irrigation. Finally, in Australia, ASCAT and AMSR2 products show a good consistency, partly also with SMOS in 2015 and 2016, but SMAP irrigation is equal to zero throughout the whole period.

A more stringent test of the results is carried out by applying the method at non-irrigated and partially irrigated pixels. Fig. 8 shows the comparison of irrigation estimates at three pilot sites in which the difference between irrigation estimates in irrigated and non-irrigated pixels is more significant. As shown before, in California the irrigation signal detected from satellite soil moisture products is evident (see also Lawston et al., 2017), and for non-irrigated pixels the irrigation is close to zero (top panels of Fig. 8). Similar differences are also observed at Castilla y León site and at Marrakech. For the other Spanish sites (not shown), at which irrigation signals are clearly detected (see Figs. 6 and 7), the differences between irrigated and non-irrigated pixels are lower (non-irrigated pixels show $30-40 \%$ less irrigation than irrigated pixels). This can be attributed to the spatial resolution of satellite observations. Indeed, even though the data are gridded at 0.25-degree sampling, the spatial resolution of SMOS, SMAP and AMSR2 are coarser (around 


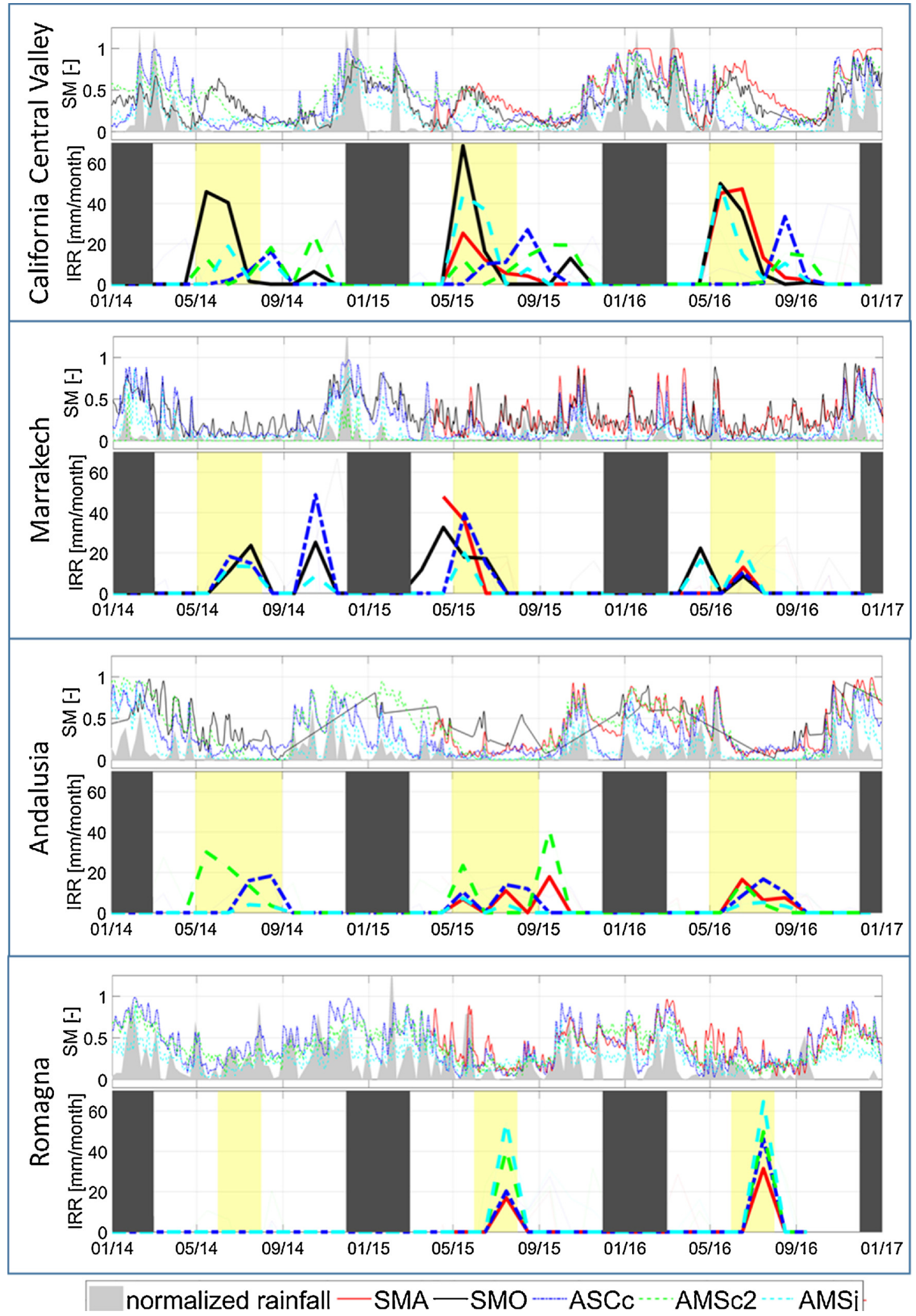

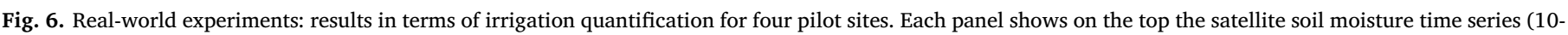

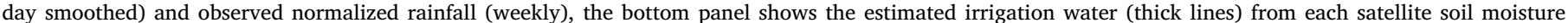

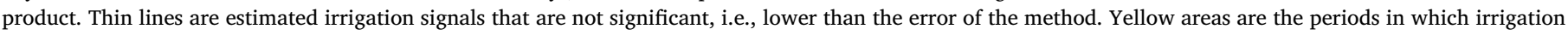

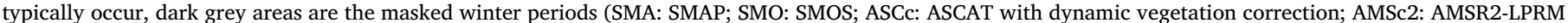

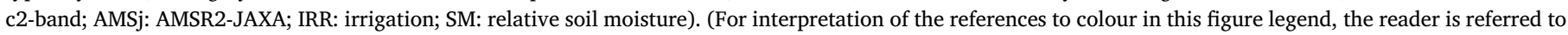
the web version of this article). 


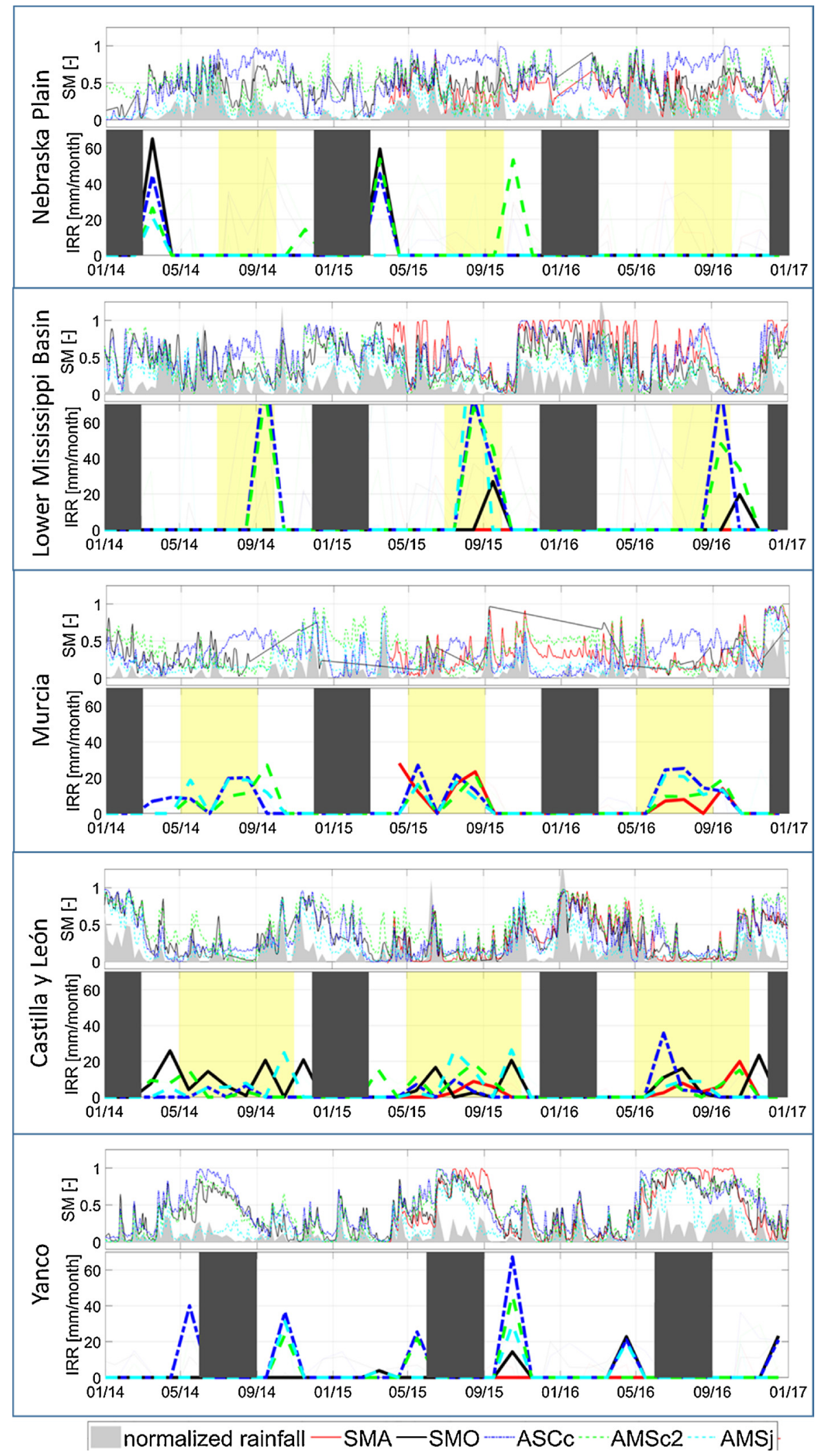

Fig. 7. As in Fig. 6 for the remaining five sites.

$40 \mathrm{~km}$ ). Also the ASCAT product is sampled to about $36 \mathrm{~km}$ resolution using a Hamming window in order to reduce noise. Therefore, the selected non-irrigated pixels are likely affected by the close irrigated ones and the assumption that no irrigation takes place is not correct. For the sites shown in Fig. 8 the non-irrigated pixels are sufficiently far from the irrigated ones to be considered as not affected by irrigation.

Finally, for the Spanish sites, an analysis at the annual scale is performed. Specifically, for each pilot site and for each soil moisture product (except SMOS in Andalusia and Murcia as it is not available), we applied our approach to irrigated and non-irrigated pixels and we 


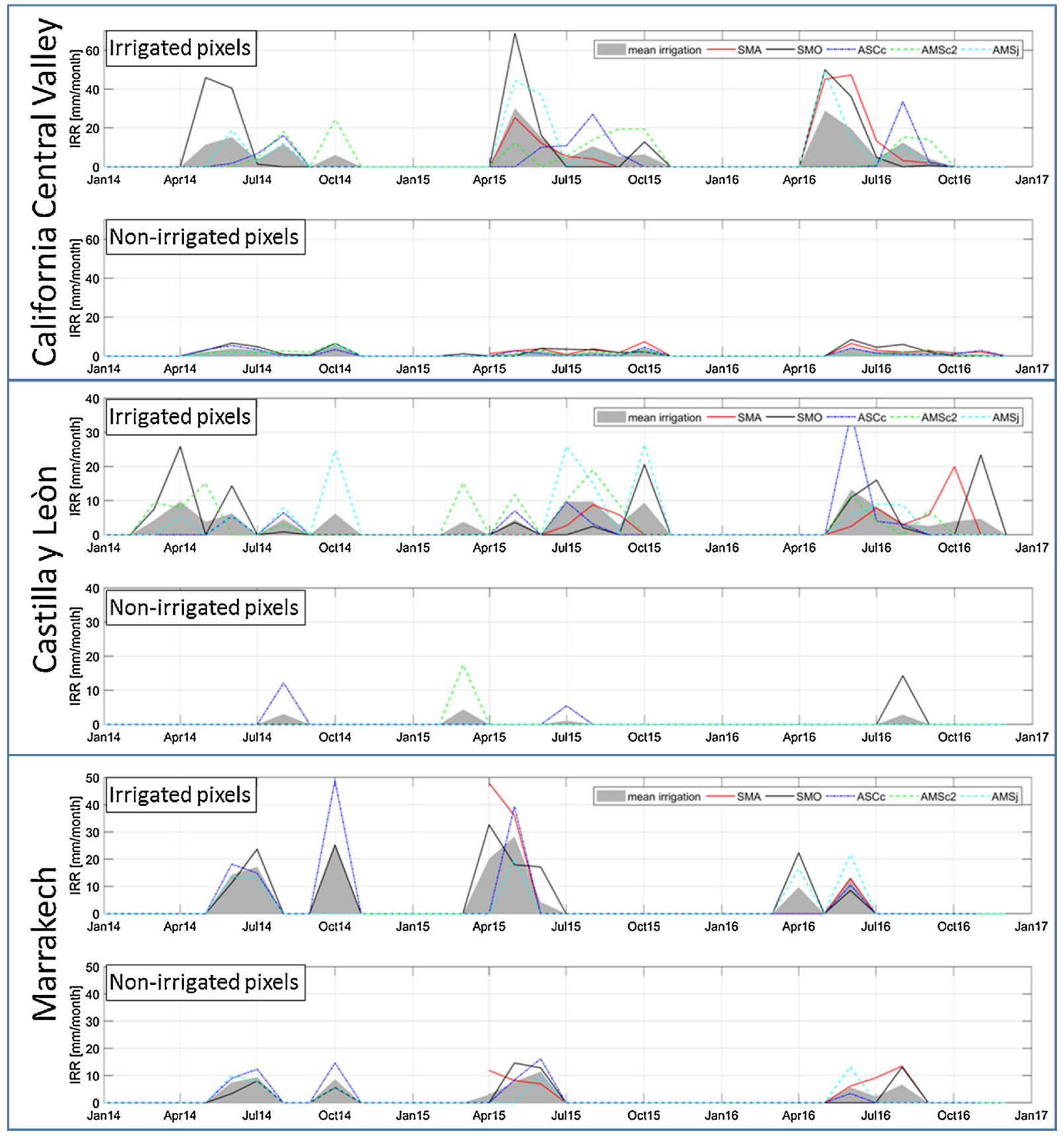

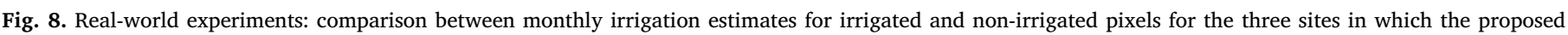

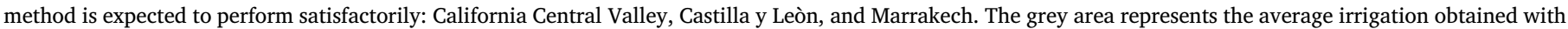

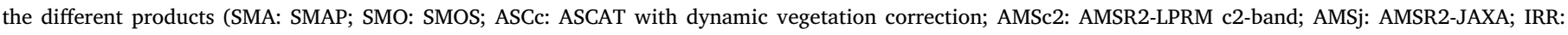
irrigation).

computed the average annual amount of irrigation for the period 20142016. Then, we computed the average annual value among all the soil moisture products that is compared with the estimates provided by the Instituto Nacional de Estadística. Results are presented in Fig. 9 and show that the two estimates have the same order of magnitude, which is between 20 and $60 \mathrm{~mm}$ /year. The proposed approach overestimates irrigation at Castilla y León region, but correctly identifies the Murcia region as the area in which the more abundant amount of irrigation is applied.

By critically analysing the obtained results, several limitations affecting the feasibility of using satellite soil moisture products for quantifying irrigation are identified. We attempt here to classify these limitations in order of relevance to underline the main points that need to be improved and further investigated. The major issue we found is related to the coarse spatial resolution of the satellite soil moisture product with respect to the size of the irrigated fields, which is consistent with earlier findings (Kumar et al., 2015; Escorihuela and Quintana-Segui, 2016). Indeed, apart from the California and the Mississippi sites, in the other sites the irrigated areas are much smaller than the actual resolution $(\sim 40 \mathrm{~km})$ of satellite soil moisture products. This makes it difficult to detect irrigation signals and, more importantly, to quantify actual irrigation amounts. The second issue is related to noise which is misinterpreted as irrigation signal by the SM2RAIN algorithm. In this study, we applied an exponential filter to reduce such effects but we believe that more tailored filtering approaches (e.g., Wavelets, Massari et al., 2017b) would have to be applied. The third issue is 


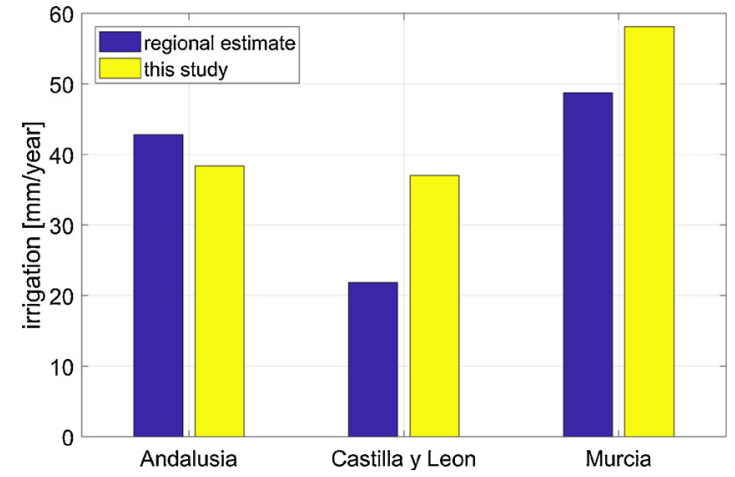

Fig. 9. Comparison of average annual irrigation values obtained from statistical surveys (Instituto Nacional de Estadística) and estimated in this study for the three pilot sites in Spain.

represented by the confounding effect of vegetation that should be disentangled from the soil moisture contribution in the retrieval algorithms of satellite soil moisture products. As evident at the California site, there is a need to clearly understand the contribution of vegetation and soil moisture over irrigated areas in which the two components are strictly linked. Finally, we found that the quality of the reference rainfall data used in Eq. (5) is a less relevant issue; we tried different rainfall products obtaining similar performances (not shown). Indeed, most irrigated areas (except rice) will operate when rainfall is at a minimum as energy at the surface (and potential evaporation) is the largest. Thus rainfall will come in spatially isolated and spurious events which replace irrigation for the farmers, and hence its impact is expected to be low.

\section{Conclusions}

In this study, we attempted to understand if coarse resolution satellite soil moisture products can be used to identify areas where irrigation is applied and, if so, to estimate the amount of water that is applied for this purpose. We therefore adopted a modified version of the SM2RAIN algorithm, which was specifically designed for this purpose. Based on the results shown above, the following conclusions can be drawn:

1) Through the synthetic experiments we assessed the reliability of the proposed approach for irrigation water quantification. Better performances are found in semi-humid climate, and the revisit time is found to be more important than the retrieval error for obtaining good accuracy. Potential evapotranspiration and soil layer depth have a null to low impact on the method performances.

2) At pilot sites, the SM2RAIN algorithm is found to perform well in reproducing monthly rainfall from satellite soil moisture observations, particularly from SMAP but also from ASCAT and AMSR2LPRM soil moisture products. The low revisit time of SMOS, and mainly RFIs at some sites, significantly hampers its use except in USA and Australia.

3) The quantification of irrigation in the real-world experiment is expected to be feasible if satellite soil moisture data have a sufficiently low uncertainty and at sites in which prolonged periods of low rainfall amounts are observed. Under these conditions, the satellite soil moisture products show good consistency with each other and might be able to reproduce the expected irrigation signal. However, it should be acknowledged that only a qualitative assessment has been carried out in this study.

4) At sites affected by snow/frozen soil conditions (Nebraska), or in which rainfall is sustained throughout the year (e.g., Mississippi and Australia), the estimation of irrigation is more difficult, if feasible at all.
As mentioned above, the main issue we found is related to the spatial resolution of the employed satellite soil moisture products. Therefore, next research activities will be addressed to the use of high resolution products, e.g., by using Sentinel-1, downscaled products (e.g., Piles et al., 2011; Zhao and Li, 2013; Peng et al., 2015; Escorihuela and Quintana-Segui, 2016) and/or new technologies (e.g., cubesats, McCabe et al., 2017, and/or Global Navigation Satellite System (GNSS) bi-static radar receivers, Chew and Small, 2018). The second major limitation of this study is the absence of comprehensive and reliable in situ irrigation observations for developing and validating more accurate approaches. We believe that an effort in this direction should be carried out by international agencies and institutions involved in the management of water resources, particularly in the agricultural sector.

The recent availability of satellite soil moisture products with increasing spatial-temporal resolution and accuracy might be an important data source for better managing water irrigation at limited costs. This study has been addressed to assess the potential of coarse resolution products, but research and project activities using high resolution and newer products are ongoing. For instance, the integration of multiple satellite soil moisture products for improving the temporal resolution of the observations is expected to improve irrigation estimates (see Tarpanelli et al. (2017) for a first example in which SM2RAIN has been applied for rainfall estimation through the integration of multiple satellite soil moisture products).

\section{Contributions}

L.B. led the manuscript, made the analysis, presented the data, and wrote the manuscript. P.F. and A.T. contributed to the development of the code and to the analysis of the soil moisture and irrigation datasets. W.D., F.Z., A.G. provided the satellite soil moisture datasets and helped with the interpretation of the numerical and experimental analysis. D.F.-P. participated to the interpretation of the global results and supervised the work. All the authors thoroughly reviewed the paper and helped the writing of the manuscript.

\section{Competing interests}

The authors declare no competing interests.

\section{Data availability}

The ESA CCI Land Cover project (https://www.esa-landcover-cci. org/), the NCEP-NCAR reanalysis project, the Australian Bureau of Meteorology (http://www.bom.gov.au/jsp/awap/), the EU-FP6 project ENSEMBLES (http://ensembles-eu.metoffice.com) the data providers in the ECA\&D project (http://www.ecad.eu), and the Italian Department of Civil Protection have provided land cover, air temperature and precipitation data used in the study. Annual irrigation values in Spain are provided by the Instituto Nacional de Estadística (through José Martinez Fernandez). The datasets generated during and/or analysed during the current study are available on request from the corresponding author.

\section{Acknowledgments}

L.B., A.T. and P.F. acknowledge the support of European Space Agency through the project WACMOS-Irrigation (ESA EXPRO RFP/314680/16/I-NB). W.D., F.Z. and A.G. received funding from the European Union Seventh Framework Programme (FP7/2007-2013) under grant agreement no. 603608, "Global Earth Observation for integrated water resource assessment": eartH2Observe. 


\section{References}

Alter, R.E., Im, E.S., Eltahir, E.A., 2015. Rainfall consistently enhanced around the Gezira Scheme in East Africa due to irrigation. Nat. Geosci. 8, 763-767.

Ambika, A.K., Wardlow, B., Mishra, V., 2016. Remotely sensed high resolution irrigated area mapping in India for 2000 to 2015. Sci. Data 3, 160118.

Bastiaanssen, W.G., Menenti, M., Feddes, R.A., Holtslag, A.A.M., 1998. A remote sensing surface energy balance algorithm for land (SEBAL). 1. Formulation. J. Hydrol. 212, 198-212.

Beck, H.E., van Dijk, A.I., Levizzani, V., Schellekens, J., Miralles, D.G., Martens, B., de Roo, A., 2017a. MSWEP: 3-hourly 0.25 global gridded precipitation (1979-2015) by merging gauge, satellite, and reanalysis data. Hydrol. Earth Syst. Sci. 21 (1), 589-615.

Beck, H.E., Vergopolan, N., Pan, M., Levizzani, V., van Dijk, A.I.J.M., Weedon, G., Brocca, L., Pappenberger, F., Huffman, G.J., Wood, E.F., 2017b. Global-scale evaluation of 22 precipitation datasets using gauge observations and hydrological modeling. Hydrol. Earth Syst. Sci. 21, 6201-6217.

Bonfils, C., Lobell, D., 2007. Empirical evidence for a recent slowdown in irrigation-induced cooling. Proc. Natl. Acad. Sci. 104 (34), 13582-13587.

Brocca, L., Melone, F., Moramarco, T., 2008. On the estimation of antecedent wetness conditions in rainfall-runoff modelling. Hydrol. Process. 22 (5), 629-642.

Brocca, L., Ciabatta, L., Massari, C., Moramarco, T., Hahn, S., Hasenauer, S., Kidd, R., Dorigo, W., Wagner, W., Levizzani, V., 2014a. Soil as a natural rain gauge: estimating global rainfall from satellite soil moisture data. J. Geophys. Res. 119 (9), 5128-5141.

Brocca, L., Camici, S., Melone, F., Moramarco, T., Martinez-Fernandez, J., Didon-Lescot, J.-F., Morbidelli, R., 2014b. Improving the representation of soil moisture by using a semi-analytical infiltration model. Hydrol. Process. 28 (4), 2103-2115.

Brocca, L., Massari, C., Ciabatta, L., Moramarco, T., Penna, D., Zuecco, G., Pianezzola, L., Borga, M., Matgen, P., Martínez-Fernández, J., 2015. Rainfall estimation from in situ soil moisture observations at several sites in Europe: an evaluation of SM2RAIN algorithm. J. Hydrol. Hydromech. 63 (3), 201-209.

Brocca, L., Pellarin, T., Crow, W.T., Ciabatta, L., Massari, C., Ryu, D., Su, C.-H., Rudiger, C., Kerr, Y., 2016. Rainfall estimation by inverting SMOS soil moisture estimates: a comparison of different methods over Australia. J. Geophys. Res. 121 (20), 12062-12079.

Brocca, L., Ciabatta, L., Massari, C., Camici, S., Tarpanelli, A., 2017. Soil moisture for hydrological applications: open questions and new opportunities. Water 9 (2), 140.

Calera, A., Campos, I., Osann, A., D’Urso, G., Menenti, M., 2017. Remote sensing for crop water management: from ET modelling to services for the end users. Sensors 17 (5), 1104.

Chew, C.C., Small, E.E., 2018. Soil moisture sensing using spaceborne GNSS reflections: comparison of CYGNSS reflectivity to SMAP soil moisture. Geophys. Res. Lett. 45 (9), 4049-4057.

Ciabatta, L., Marra, A.C., Panegrossi, G., Casella, D., Sanò, P., Dietrich, S., Massari, C., Brocca, L. 2017. Daily precipitation estimation through different microwave sensors: verification study over Italy. J. Hydrol. 545, 436-450.

Deines, J.M., Kendall, A.D., Hyndman, D.W., 2017. Annual irrigation dynamics in the US Northern High Plains derived from Landsat satellite data. Geophys. Res. Lett. 44 (18), 9350-9360.

Döll, P., Siebert, S., 2002. Global modeling of irrigation water requirements. Water Resour. Res. 38 (4), 8.1-8.10.

Doorenbos, J., Pruitt, W.O., 1977. Background and development of methods to predict reference crop evapotranspiration (ETo). FAO-ID-24, Appendix II. pp. 108-119.

Droogers, P., Immerzeel, W.W., Lorite, I.J., 2010. Estimating actual irrigation application by remotely sensed evapotranspiration observations. Agric. Water Manage. 97 (9), 1351-1359.

Entekhabi, D., Njoku, E.G., Neill, P.E., Kellogg, K.H., Crow, W.T., Edelstein, W.N., et al., 2010. The soil moisture active passive (SMAP) mission. Proceedings of the IEEE 2010, vol. 98 (5), 704-716.

Escorihuela, M.J., Quintana-Segui, P., 2016. Comparison of remote sensing and simulated soil moisture datasets in Mediterranean landscapes. Remote Sens. Environ. 180, 99-114.

FAO, 2006. AQUASTAT Online Database. Available at:. Food and Agriculture Organization of the United Nations (FAO). http://www.fao.org/ag/agl/aglw/ aquastat/main/index.stm.

Ferrant, S., Selles, A., Le Page, M., Herrault, P.A., Pelletier, C., Al-Bitar, A., et al., 2017. Detection of irrigated crops from Sentinel-1 and Sentinel-2 data to estimate seasonal groundwater use in South India. Remote Sens. 9 (11), 1119.

Foley, J.A., Ramankutty, N., Brauman, K.A., Cassidy, E.S., Gerber, J.S., Johnston, M., et al., 2011. Solutions for a cultivated planet. Nature 478 (7369), 337-342.

Hahn, S., Reimer, C., Vreugdenhil, M., Melzer, T., Wagner, W., 2017. Dynamic characterization of the incidence angle dependence of backscatter using Metop ASCAT. IEEE J. Sel. Top. Appl. Earth Observ. Remote Sens. 10 (5), 2348-2359.

Haylock, M.R., Hofstra, N., Klein Tank, A.M.G., Klok, E.J., Jones, P.D., New, M., 2008. A European daily high-resolution gridded data set of surface temperature and precipitation for 1950-2006. J. Geophys. Res. Atmos. 113 (D20).

He, L., Chen, J.M., Liu, J., Bélair, S., Luo, X., 2017. Assessment of SMAP soil moisture for global simulation of gross primary production. J. Geophys. Res. Biogeosci. 122 (7), 1549-1563.

Jalilvand, E., Tajrishy, M., Hashemi, S.A.G., Brocca, L. (under review). Quantification of irrigation water using remote sensing of soil moisture in a semi-arid area. Submitted to Remote Sensing of Environment.

Jones, D.A., Wang, W., Fawcett, R., 2009. High-quality spatial climate data-sets for Australia. Aust. Meteorol. Oceanogr. J. 58, 233-248.

Kalnay, E., Kanamitsu, M., Kistler, R., Collins, W., Deaven, D., Gandin, L., et al., 1996. The
NCEP/NCAR 40-year reanalysis project. Bull. Am. Meteorol. Soc. 77 (3), 437-471.

Kerr, Y.H., Waldteufel, P., Wigneron, J.-P., Martinuzzi, J., Font, J., Berger, M., 2001. Soil moisture retrieval from space: the Soil Moisture and Ocean Salinity (SMOS) mission. IEEE Trans. Geosci. Remote Sens. 39, 1729-1735.

Kim, S., Liu, Y.Y., Johnson, F.M., Parinussa, R.M., Sharma, A., 2015. A global comparison of alternate AMSR2 soil moisture products: why do they differ? Remote Sens. Environ. 161, 43-62.

Koster, R.D., Brocca, L., Crow, W.T., Burgin, M.S., De Lannoy, G.J.M., 2016. Precipitation estimation using L-Band and C-Band soil moisture retrievals. Water Resour. Res. 52 (9), 7213-7225.

Kumar, S.V., Peters-Lidard, C.D., Santanello, J.A., Reichle, R.H., Draper, C.S., Koster, R.D., 2015. Evaluating the utility of satellite soil moisture retrievals over irrigated areas and the ability of land data assimilation methods to correct for unmodeled processes. Hydrol. Earth Syst. Sci. 19, 4463-4478.

Kummu, M., Guillaume, J.H.A., De Moel, H., Eisner, S., Flörke, M., Porkka, M., et al., 2016. The world's road to water scarcity: shortage and stress in the 20th century and pathways towards sustainability. Sci. Rep. 6, 38495.

Lawston, P.M., Santanello, J.A., Kumar, S.V., 2017. Irrigation signals detected from SMAP soil moisture retrievals. Geophys. Res. Lett. 44 (23), 11860-11867.

Malbéteau, Y., Merlin, O., Balsamo, G., Er-Raki, S., Khabba, S., Walker, J.P., Jarlan, L. 2018. Towards a surface soil moisture product at high spatio-temporal resolution: temporally-interpolated spatially-disaggregated SMOS data. J. Hydrometeorol. 19 (1), 183-200.

Martinez-Fernandez, J., Ceballos, A., 2005. Mean soil moisture estimation using temporal stability analysis. J. Hydrol. 312 (1-4), 28-38.

Massari, C., Crow, W., Brocca, L., 2017a. An assessment of the accuracy of global rainfall estimates without ground-based observations. Hydrol. Earth Syst. Sci. 21, 4347-4361.

Massari, C., Su, C.-H., Brocca, L., Sang, Y.F., Ciabatta, L., Ryu, D., Wagner, W., 2017b. Near real time de-noising of satellite-based soil moisture retrievals : an intercomparison among three different techniques. Remote Sens. Environ. 198, 17-29.

McCabe, M.F., Aragon, B., Houborg, R., Mascaro, J., 2017. CubeSats in hydrology: ultra-high resolution insights into vegetation dynamics and terrestrial evaporation. Water Resour. Res. 53 (12), 10017-10024.

Morbidelli, R., Corradini, C., Saltalippi, C., Flammini, A., Rossi, E., 2011. Infiltration-soil moisture redistribution under natural conditions: experimental evidence as a guideline for realizing simulation models. Hydrol. Earth Syst. Sci. 15, 2937-2945.

Owe, M., De Jeu, R.A.M., Holmes, T.R.H., 2008. Multi-sensor historical climatology of satellite-derived global land surface moisture. J. Geophys. Res. 113 F01002.

Ozdogan, M., Gutman, G., 2008. A new methodology to map irrigated areas using multitemporal MODIS and ancillary data: An application example in the continental US. Remote Sens. Environ. 112, 3520-3537.

Ozdogan, M., Woodcock, C.E., Salvucci, G.D., Demir, H., 2006. Changes in summer irrigated crop area and water use in Southeastern Turkey from 1993 to 2002: implications for current and future water resources. Water Resour. Manage. 20 (3), 467-488.

Ozdogan, M., Yang, Y., Allez, G., Cervantes, C., 2010. Remote sensing of irrigated agriculture: opportunities and challenges. Remote Sens. 2 (9), 2274-2304.

Peng, J., Niesel, J., Loew, A., 2015. Evaluation of soil moisture downscaling using a simple thermal-based proxy-the REMEDHUS network (Spain) example. Hydrol. Earth Syst. Sci. 19 (12), 4765-4782.

Pervez, M.S., Budde, M., Rowland, J., 2014. Mapping irrigated areas in Afghanistan over the past decade using MODIS NDVI. Remote Sens. Environ. 149, 155-165.

Piles, M., Camps, A., Vall-Llossera, M., Corbella, I., Panciera, R., Rudiger, C., et al., 2011. Downscaling SMOS-derived soil moisture using MODIS visible/infrared data. IEEE Trans. Geosci. Remote Sens. 49 (9), 3156-3166.

Pun, M., Mutiibwa, D., Li, R., 2017. Land use classification: a surface energy balance and vegetation index application to map and monitor irrigated lands. Remote Sens. 9 (12), 1256.

Qiu, J., Gao, Q., Wang, S., Su, Z., 2016. Comparison of temporal trends from multiple soil moisture data sets and precipitation: the implication of irrigation on regional soil moisture trend. Int. J. Appl. Earth Observ. Geoinf. 48, 17-27.

Rockström, J., Falkenmark, M., Lannerstad, M., Karlberg, L., 2012. The planetary water drama: dual task of feeding humanity and curbing climate change. Geophys. Res. Lett. 39 L14403.

Romaguera, M., Hoekstra, A.Y., Su, Z., Krol, M.S., Salama, M.S., 2010. Potential of using remote sensing techniques for global assessment of water footprint of crops. Remote Sens. 2 (4), 1177-1196.

Romaguera, M., Krol, M.S., Salama, M., Hoekstra, A.Y., Su, Z., 2012. Determining irrigated areas and quantifying blue water use in Europe using remote sensing Meteosat Second Generation (MSG) products and Global Land Data Assimilation System (GLDAS) data. Photogramm. Eng. Remote Sens. 78 (8), 861-873.

Salmon, J.M., Friedl, M.A., Frolking, S., Wisser, D., Douglas, E.M., 2015. Global rain-fed, irrigated, and paddy croplands: a new high resolution map derived from remote sensing, crop inventories and climate data. Int. J. Appl. Earth Observ. Geoinf. 38, 321-334.

Siebert, S., Kummu, M., Porkka, M., Döll, P., Ramankutty, N., Scanlon, B.R., 2015. A global data set of the extent of irrigated land from 1900 to 2005. Hydrol. Earth Syst. Sci. 19, 1521-1545.

Singh, D., Gupta, P.K., Pradhan, R., Dubey, A.K., Singh, R.P., 2017. Discerning shifting irrigation practices from passive microwave radiometry over Punjab and Haryana. J. Water Clim. Change 8 (2), 303-319.

Smith, A.B., Walker, J.P., Western, A.W., Young, R.I., Ellett, K.M., Pipunic, R.C., et al., 2012. The Murrumbidgee soil moisture monitoring network data set. Water Resour. Res. 48 (7) W07701.

Tarpanelli, A., Massari, C., Ciabatta, L., Filippucci, P., Amarnath, G., Brocca, L., 2017. Exploiting a constellation of satellite soil moisture sensors for accurate rainfall 
estimation. Adv. Water Resour. 108, 249-255.

Teluguntla, P., Thenkabail, P.S., Xiong, J., Gumma, M.K., Congalton, R.G., Oliphant, A., et al., 2017. Spectral matching techniques (SMTs) and automated cropland classification algorithms (ACCAs) for mapping croplands of Australia using MODIS 250-m time-series (2000-2015) data. Int. J. Digit. Earth 8947, 1-34.

Tian, Y., Huffman, G.J., Adler, R.F., Tang, L., Sapiano, M., Maggioni, V., Wu, H., 2013. Modeling errors in daily precipitation measurements: additive or multiplicative? Geophys. Res. Lett. 40 (10), 2060-2065.

van Dijk, A.I.J.M., Schellekens, J., Yebra, M., Beck, H.E., Renzullo, L.J., Weerts, A Donchyts, G., 2018. Global 5-km resolution estimates of secondary evaporation including irrigation through satellite data assimilation. Hydrol. Earth Syst. Sci. Discuss. https://doi.org/10.5194/hess-2017-757. in review.

Van Eekelen, M.W., Bastiaanssen, W.G., Jarmain, C., Jackson, B., Ferreira, F., Van der Zaag, P., et al., 2015. A novel approach to estimate direct and indirect water with drawals from satellite measurements: a case study from the Incomati basin. Agric. Ecosyst. Environ. 200, 126-142.

Vörösmarty, C.J., Green, P., Salisbury, J., Lammers, R.B., 2000. Global water resources: vulnerability from climate change and population growth. Science 289, 284-288.

Vreugdenhil, M., Dorigo, W.A., Wagner, W., de Jeu, R.A.M., Hahn, S., van Marle, M.J., 2016. Analyzing the vegetation parameterization in the TU-Wien ASCAT soil moisture retrieval. IEEE Trans. Geosci. Remote Sens. 54 (6), 3513-3531.
Wada, Y., Wisser, D., Bierkens, M.F.P., 2014. Global modeling of withdrawal, allocation and consumptive use of surface water and groundwater resources. Earth Syst. Dyn. 5 (1), 15-40.

Wagner, W., Lemoine, G., Rott, H., 1999. A method for estimating soil moisture from ERS scatterometer and soil data. Remote Sens. Environ. 70 (2), 191-207.

Wagner, W., Hahn, S., Kidd, R., Melzer, T., Bartalis, Z., Hasenauer, S., Figa, J., de Rosnay, P., Jann, A., Schneider, S., Komma, J., Kubu, G., Brugger, K., Aubrecht, C., Zuger, J., Gangkofner, U., Kienberger, S., Brocca, L., Wang, Y., Bloeschl, G., Eitzinger, J.,

Steinnocher, K., Zeil, P., Rubel, F., 2013. The ASCAT soil moisture product: a review of its specifications, validation results, and emerging applications. Meteorologische Zeitschrift 22 (1), 5-33.

Wu, X., Zhou, J., Wang, H., Li, Y., Zhong, B., 2015. Evaluation of irrigation water use efficiency using remote sensing in the middle reach of the Heihe river, in the semi-arid Northwestern China. Hydrol. Process. 29 (9), 2243-2257.

Zaussinger, F., Dorigo, W., Gruber, A., Tarpanelli, A., Filippucci, P., Brocca, L., 2018. Estimating irrigation water use over the contiguous United States by combining satellite and reanalysis soil moisture data. Hydrol. Earth Syst. Sci. Discuss. https://doi org/10.5194/hess-2018-388. in review.

Zhao, W., Li, A., 2013. A downscaling method for improving the spatial resolution of AMSR-E derived soil moisture product based on MSG-SEVIRI data. Remote Sens. 5 (12), 6790-6811. 